\title{
TEP for elective primary unilateral inguinal hernia repair in men: what do we know?
}

\author{
F. Köckerling ${ }^{1}$
}

Received: 11 March 2019 / Accepted: 26 March 2019 / Published online: 6 May 2019

(c) The Author(s) 2019

\begin{abstract}
Introduction Based on the new international guidelines for groin hernia management, there is no one surgical technique that is suited to all patient characteristics and diagnostic findings. Therefore, a tailored approach should be used. Here, a distinction must be made between primary unilateral inguinal hernia in men and in women, bilateral inguinal hernia, scrotal inguinal hernia, inguinal hernia following pelvic and lower abdominal procedures, patients with severe cardiopulmonary complications, recurrent inguinal hernias and incarcerated inguinal and femoral hernias. This paper now explores the relevant studies on TEP for elective primary unilateral inguinal hernia in men, which constitutes the most common indication for repair.

Material A systematic search of the available literature was performed in February 2019 using Medline, PubMed, Scopus, Embase, Springer Link and the Cochrane Library. Only meta-analyses, systematic reviews, RCTs and comparative registry studies were considered. 117 publications were identified as relevant.

Results RCTs and comparative registry analyses demonstrated the advantages of TEP with regard to postoperative complications, complication-related reoperations, and postoperative and chronic pain compared with Lichtenstein repair for elective primary unilateral inguinal hernia repair in men. No relevant differences were found compared with TAPP. Mesh fixation is not needed in TEP, but heavyweight meshes result in a lower recurrence rate. Extraperitoneal bupivacaine analgesia vs placebo does not demonstrate any advantages, but drainage is advantageous for seroma prophylaxis. The risk of chronic pain is negatively influenced by small defects, younger patient age, preoperative pain, higher BMI, postoperative complications, higher ASA score and risk factors.

Conclusion For the subgroup of elective primary unilateral inguinal hernia in men, accounting for a proportion of less than $50 \%$ of the total collective, advantages were identified for TEP compared with open Lichtenstein repair but not versus TAPP.
\end{abstract}

Keywords Inguinal hernia $\cdot$ TEP $\cdot$ Recurrence $\cdot$ Chronic pain $\cdot$ Postoperative complications $\cdot$ Costs

\section{Introduction}

Using evidence-based guidelines and recommendations, the international hernia societies are trying to improve the quality of hernia surgery through standardization of treatment [1-6]. The more than 100 different techniques described for repair of inguinal or femoral hernia are classified as open

The article is part of the Topical Collection "Forum on primary monolateral uncomplicated inguinal herna".

F. Köckerling

ferdinand.koeckerling@vivantes.de

1 Department of Surgery and Center for Minimally Invasive Surgery, Academic Teaching Hospital of Charité Medical School, Vivantes Hospital, Neue Bergstrasse 6, 13585 Berlin, Germany tissue repair, open mesh repair and laparoendoscopic mesh repair [7]. The new international guidelines of the HerniaSurge Group now only recommend the laparoendoscopic total extraperitoneal patch plasty (TEP) and transabdominal preperitoneal patch plasty (TAPP) techniques, open anterior Lichtenstein mesh repair and with limitations the mesh-free, open tissue Shouldice repair technique [6]. In that respect, the new international guidelines of the HerniaSurge Group point out that there is no one surgical technique best suited to all clinical scenarios [6].

Accordingly, the guidelines urgently recommend that surgeons adopt a tailored approach for inguinal hernia repair [6-8]. In doing so, a distinction must be made between primary unilateral inguinal hernia in men versus women, bilateral inguinal hernias, scrotal inguinal hernias, inguinal hernias after previous pelvic and lower abdominal surgery, 
inguinal hernias in patients with severe cardiac or pulmonary comorbidities and incarcerated inguinal hernias [6-8]. Since the proportion of women in the overall patient collective of inguinal and femoral hernias is around $10 \%$, the proportion of recurrences is likewise around $10 \%$ and the proportion of bilateral inguinal and femoral hernias is around $20 \%[9,10]$, elective primary unilateral inguinal hernia repair in men, accounting for a proportion of less than $50 \%$, is the standard procedure for repair of inguinal and femoral hernias [6-8]. Due to the fact that the outcomes for repair of inguinal hernia recurrences, bilateral inguinal hernias, scrotal hernias as well as for inguinal and femoral hernias in women are less favorable [9, 11, 12], the basis used for method comparison and for performance assessment should, first of all, be an inguinal hernia repair technique based on the data available for elective primary unilateral inguinal hernia in men [6].

The data available for elective primary unilateral inguinal hernia repair in men with the TEP technique are now explored in the following.

\section{Materials and methods}

A systematic search of the available literature was performed in February 2019 using Medline, PubMed, Scopus, Embase, Springer Link and the Cochrane Library as well as a search of relevant journals and reference lists. The following search terms were used: "total extraperitoneal patchplasty", "TEP", "TEP hernia", "Inguinal hernia and TEP". The titles and abstracts of 688 publications were screened (Fig. 1).

Based on the key question, only studies reporting exclusively on elective primary unilateral inguinal hernias in men could be included. Furthermore, only studies with level of evidence 1 and 2 as per the Oxford Hierarchy of Evidence were included, i.e., meta-analyses, systematic reviews, prospective randomized controlled trials (RCTs) and comparative registry studies.

The present analysis identified 117 publications as relevant for this review. A systematic presentation and synthesis of the characteristics and findings of the included studies have been made in accordance with the Prisma guidelines [13].

\section{Results}

\section{Comparison of TEP vs Lichtenstein in meta-analyses and RCTs}

There are already two meta-analyses focusing exclusively on the comparison of the totally extraperitoneal patch plasty (TEP) with the Lichtenstein technique.

In a systematic review with meta-analysis and trial sequential analyses of randomized clinical trials, 5404
Fig. 1 Flowchart of study inclusion

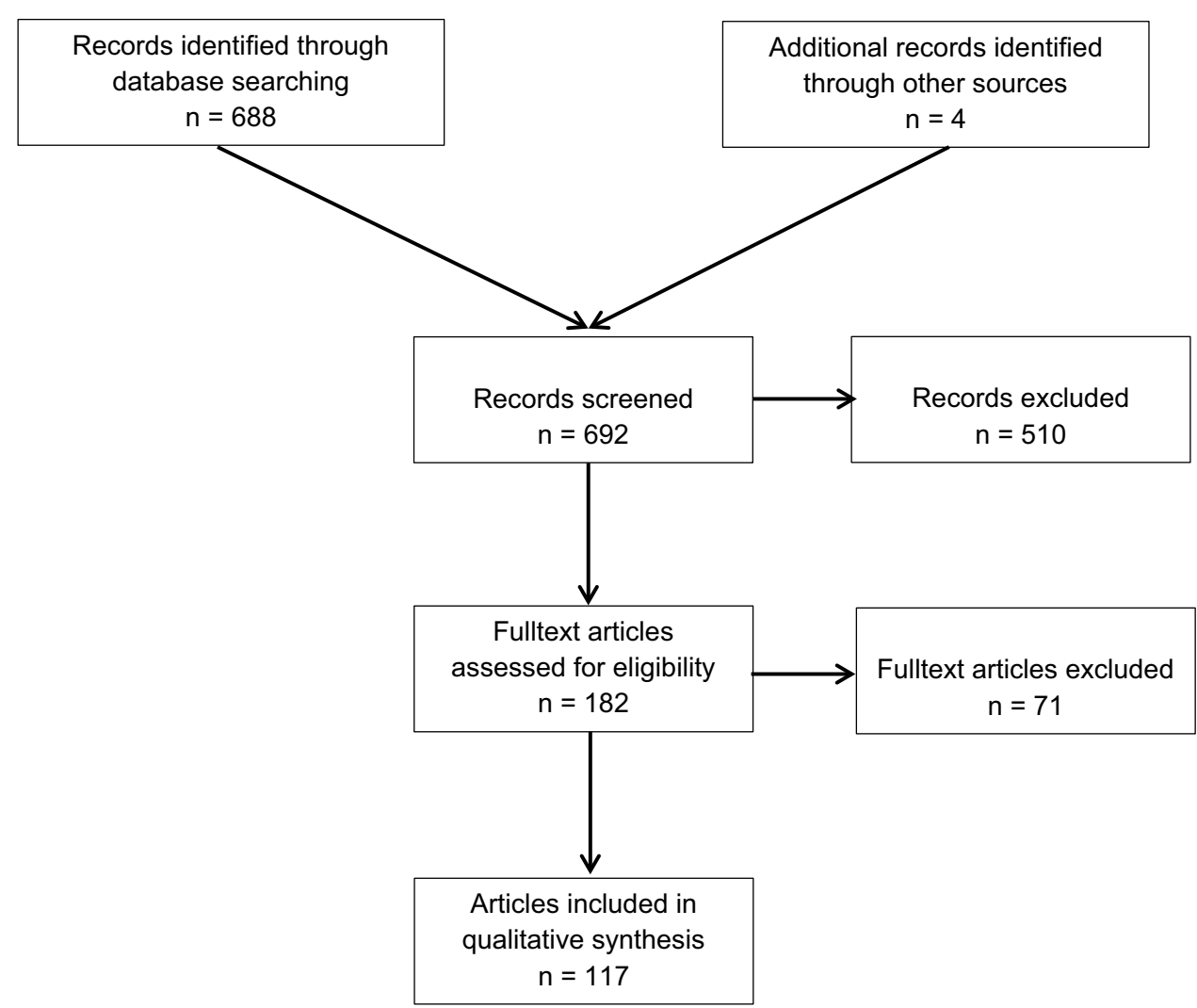


patients from 13 studies were included [14]. There was no significant effect of TEP compared with the Lichtenstein on the number of patients with chronic pain in a random-effects model risk ratio (RR 0.80; 95\% CI 0.61-1.04; $p=0.09$ ), nor was there any significant effect on the number of patients with recurrences in a random-effects model (RR 1.41; 95\% CI $0.72-2.27 ; p=0.32$ ), and the TEP technique may or may not be associated with less severe adverse events (randomeffects model RR $0.91 ; 95 \%$ CI $0.73-1.12 ; p=0.37$ ). Trial sequential analysis showed that the required information size was far from reached for important patient outcomes. The authors concluded that TEP versus Lichtenstein for inguinal hernia repair has been evaluated by 13 trials with high risk of bias. The review with meta-analyses, trial sequential analyses and error matrix approach shows no conclusive evidence of a difference between TEP and Lichtenstein on the primary outcomes chronic pain, recurrences and severe adverse events.

The meta-analysis evaluated the following RCTs: Andersson [15], Colak [16], Eklund [17], Gokalp [18], Heikkinen [19], Hildebrand [20], Merello [21], Moreno-Egea [22], Neumayer [23], Lal [24], Langeveld [25], Lau [26], and Wright [27].

Analysis of the inclusion and exclusion criteria showed for the studies $[15,16,20-25,27]$ that women or bilateral hernias or recurrent inguinal hernias were included. Hence, such studies are not suitable for comparing TEP with the Lichtenstein operation for primary unilateral inguinal hernia in male patients. As such, that leaves only the studies $[17-19,26]$ to answer the question addressed in this present analysis.

Another meta-analysis of randomized controlled trials comparing Lichtenstein and TEP for treatment of inguinal hernias included 13 RCTs with 3279 patients [28]. That meta-analysis also contained the studies [18, 19, 24-26] and additionally the studies of Wang [29], Kouhia [30], Eklund [31, 32], Hallen [33], Pokorny [34], Zhiping [35], Dedemadi [36] and Bringman [37].

If one compares the two meta-analyses on the basis of the included studies, one notes that only six studies [17-19, 24-26, 31, 32] were taken into account in both meta-analyses. Besides, the Eklund study [17] featured in the metaanalysis by Konig [14] takes account only of the short-term outcome, while the meta-analysis by Bobo [28] focuses only on long-term outcome [31, 32].

As pointed out above, to explore the question of comparing TEP vs Lichtenstein for primary unilateral inguinal hernia repair in men, these studies that included women, bilateral hernias and recurrent hernias had to be excluded [24, 25, 29, 30, 33-37].

Therefore, from the two meta-analyses in addition to the aforementioned studies by Eklund [17], Gokalp [18],
Heikkinen [19] and Can [26], there remains only that by Eklund [31, 32].

Other studies (which were not taken into consideration in either of the two meta-analyses) which could potentially lend themselves to answering this key question included one cost analysis contained in the Eklund study [38]. In addition, there was a four-arm randomized trial comparing laparoscopic and open hernia repairs [39] as well as two studies comparing TEP under general anesthesia vs Lichtenstein under local anesthesia [40, 41]. It was not possible either to include the long-term outcome of the Langeveld study [42], since that study with 660 patients focused on bilateral inguinal hernias and recurrences.

The details and outcome of studies (1096 TEP procedures vs 1141 Lichtenstein procedures) consulted for answering the questions are listed in Table 1.

In the study by Eklund et al. [17], a total of 1513 men from 11 hospitals who presented with a primary unilateral inguinal hernia were randomized to TEP or Lichtenstein. 1371 of the 1513 men underwent surgery, 665 in the TEP group and 706 in the Lichtenstein group. The median duration of operation was 55 min for both procedures and $91.0 \%$ of the patients in both groups were discharged on the day of operation. The overall operative and postoperative complication rate was not significantly different between the two groups (TEP $12.2 \%$ vs Lichtenstein 12.3\%). Patients in the TEP group experienced less postoperative pain on days $1,2,35,7$ and 14 $(p<0.001)$, consumed fewer analgesics on days $1,2,3$, 5 and $7(p<0.001)$, had a shorter period of sick leave $(7$ versus 12 days; $p<0.001)$ and a shorter time to resumption of normal physical activity ( 20 versus 31 days; $p<0.001$ ).

In the study by Lau et al. [26], a total of 200 male patients with primary unilateral inguinal hernia were randomized to undergo either day case unilateral TEP $(n=100)$ or open Lichtenstein $(n=100)$ hernioplasty under general anesthesia. The mean operating time for TEP $(50 \pm 13.2 \mathrm{~min})$ was significantly shorter than for open Lichtenstein hernioplasty $(58 \pm 17.6 \mathrm{~min})(p<0.001)$. The postoperative complication rate was $15 \%$ for both procedures. The pain score at rest was significantly lower in the TEP group than in the open group on postoperative days $0,1,4,5$ and 6 . On average, patients returned to work 8.6 days after TEP and 14 days after Lichtenstein hernioplasty $(p=0.006)$. Postoperative recovery was comparable between the two groups.

In the study by Heikkinen et al. [19], 45 employed men with a primary unilateral inguinal hernia were randomized to undergo either a TEP $(n=22)$ or a Lichtenstein operation $(n=23)$. The operating time was shorter in the Lichtenstein group (67.5 min, range 40-88 min vs $53 \mathrm{~min}$, range $42-48$ $\min ; p=0.001)$. The mean daily pain score for 2 weeks was significantly lower for TEP $(p<0.05)$. There was no 


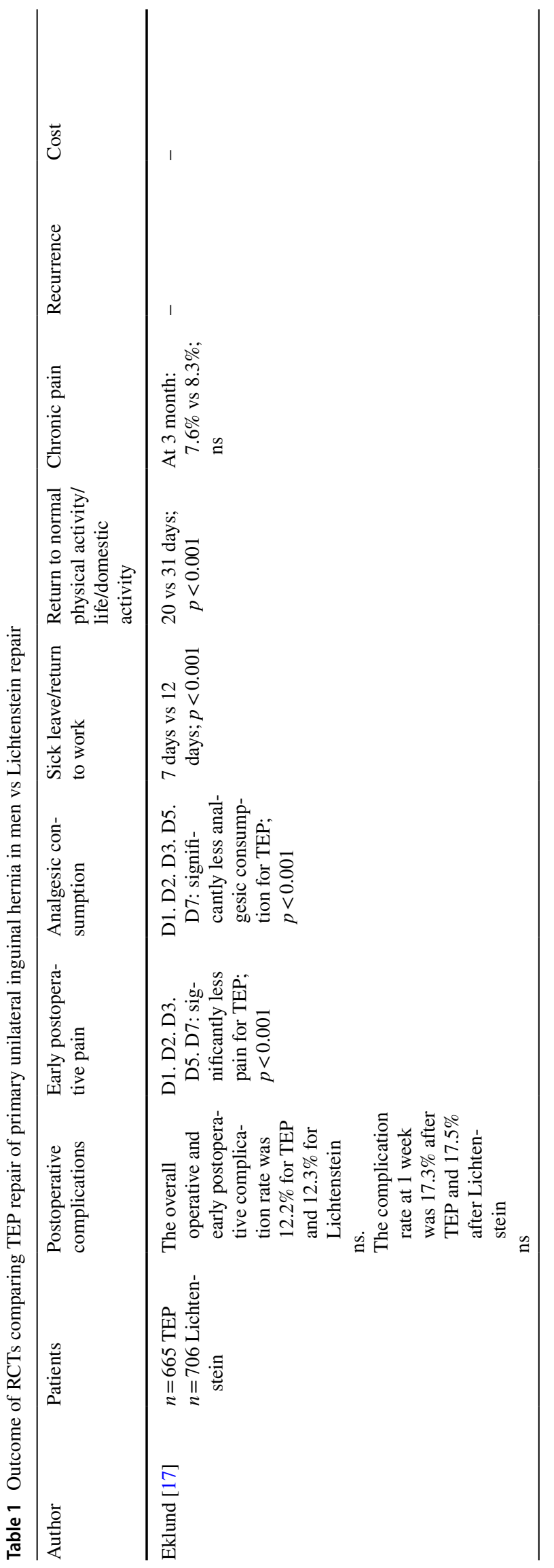




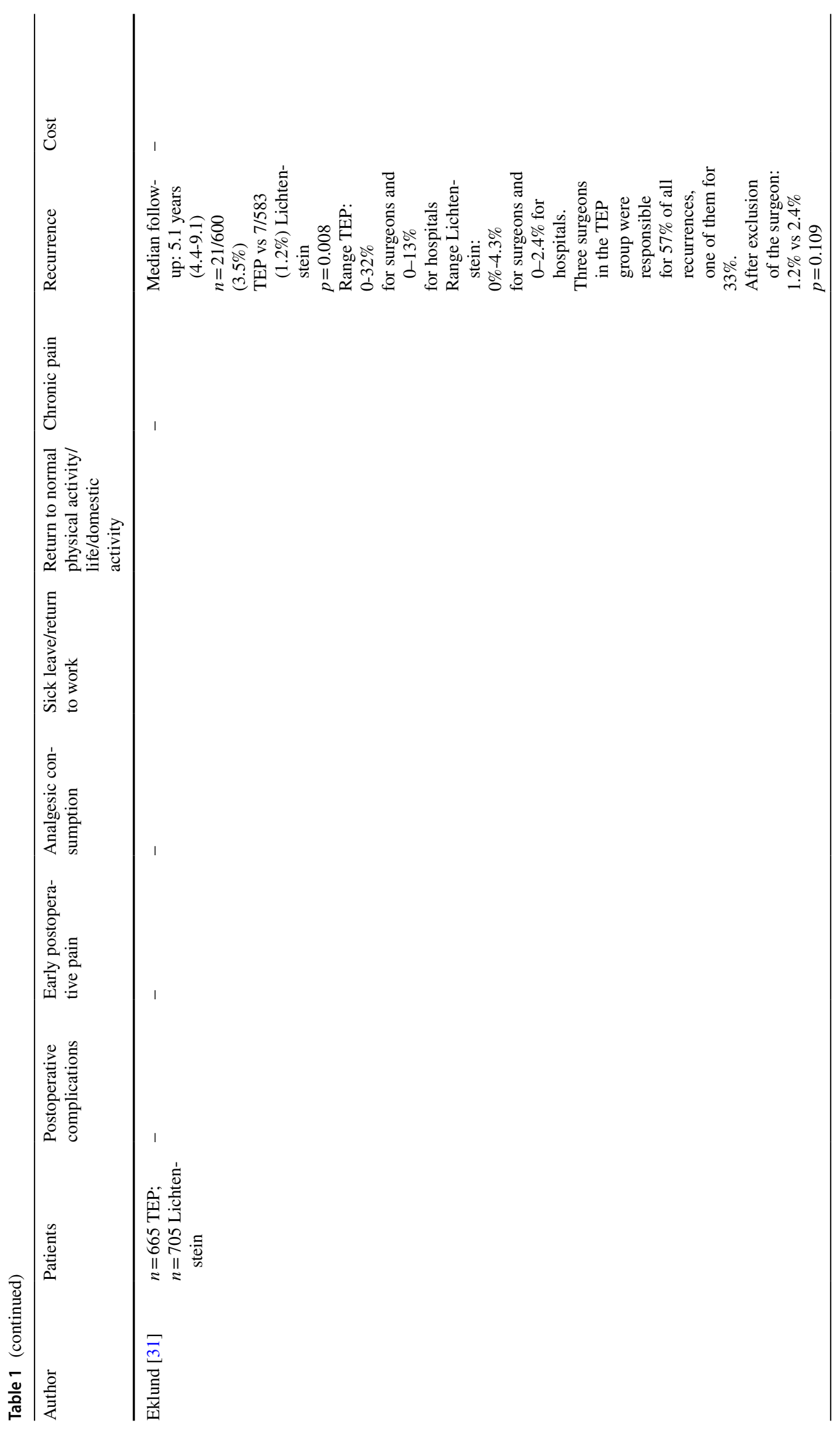




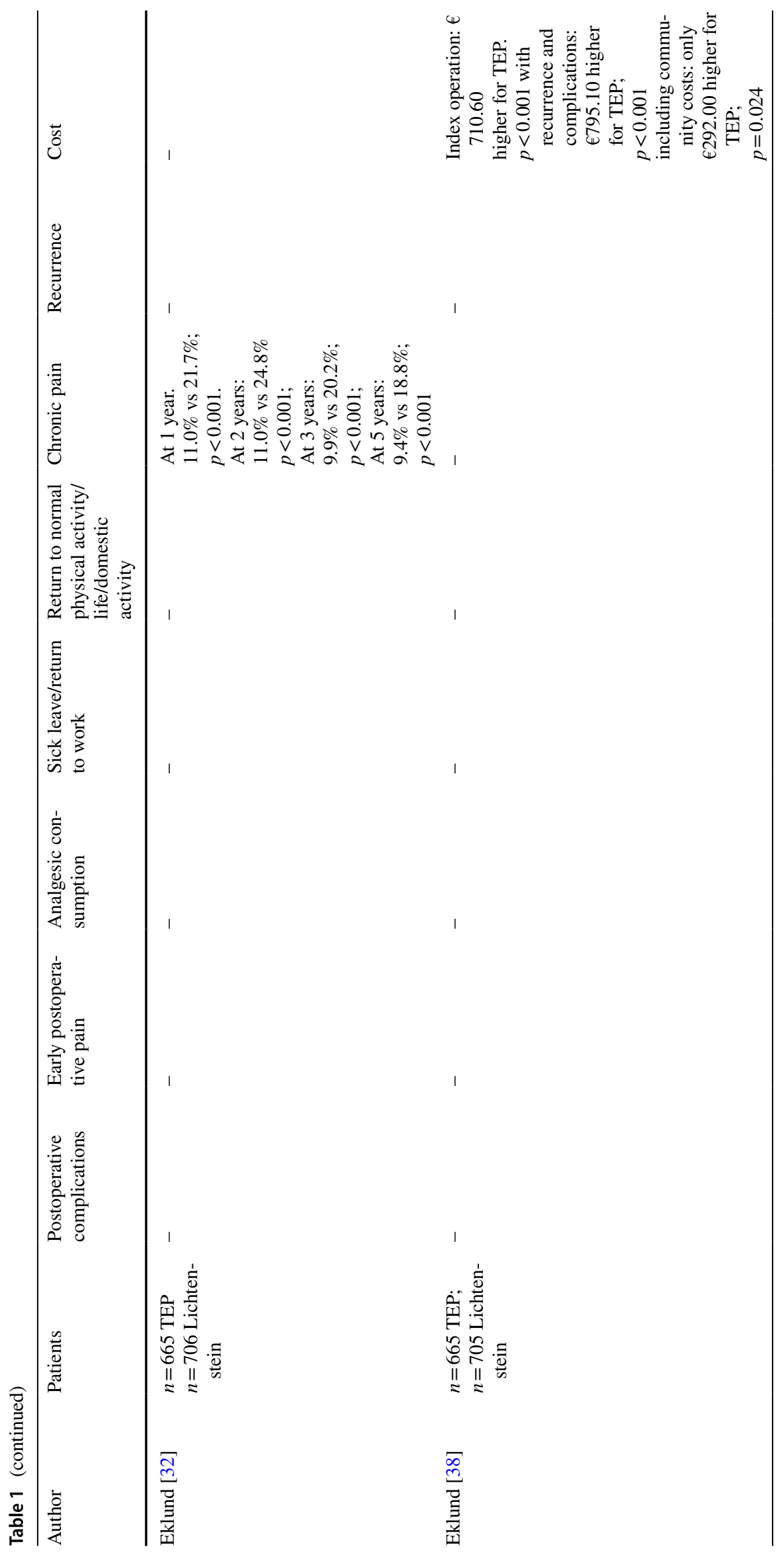

望 Springer 


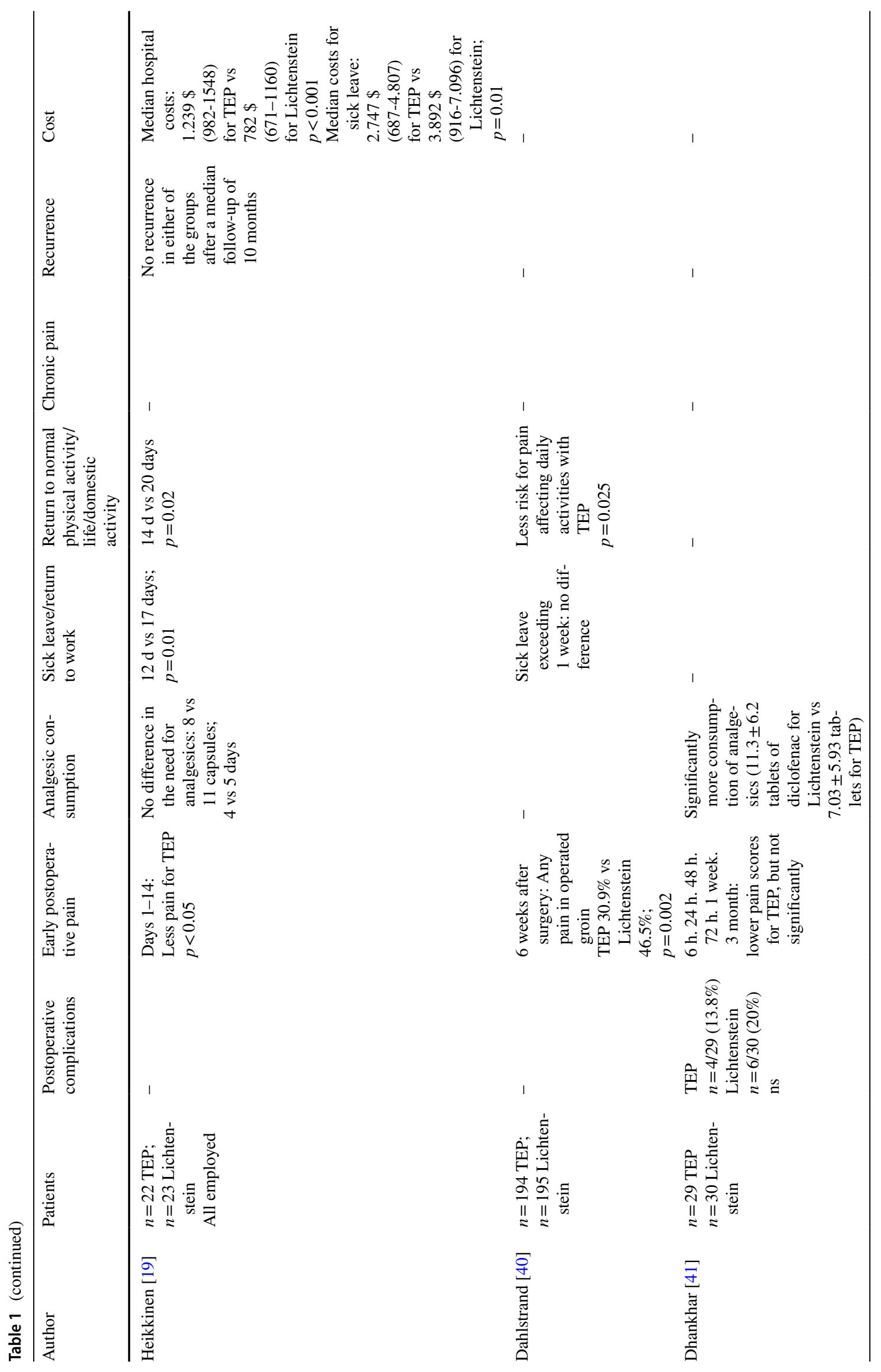




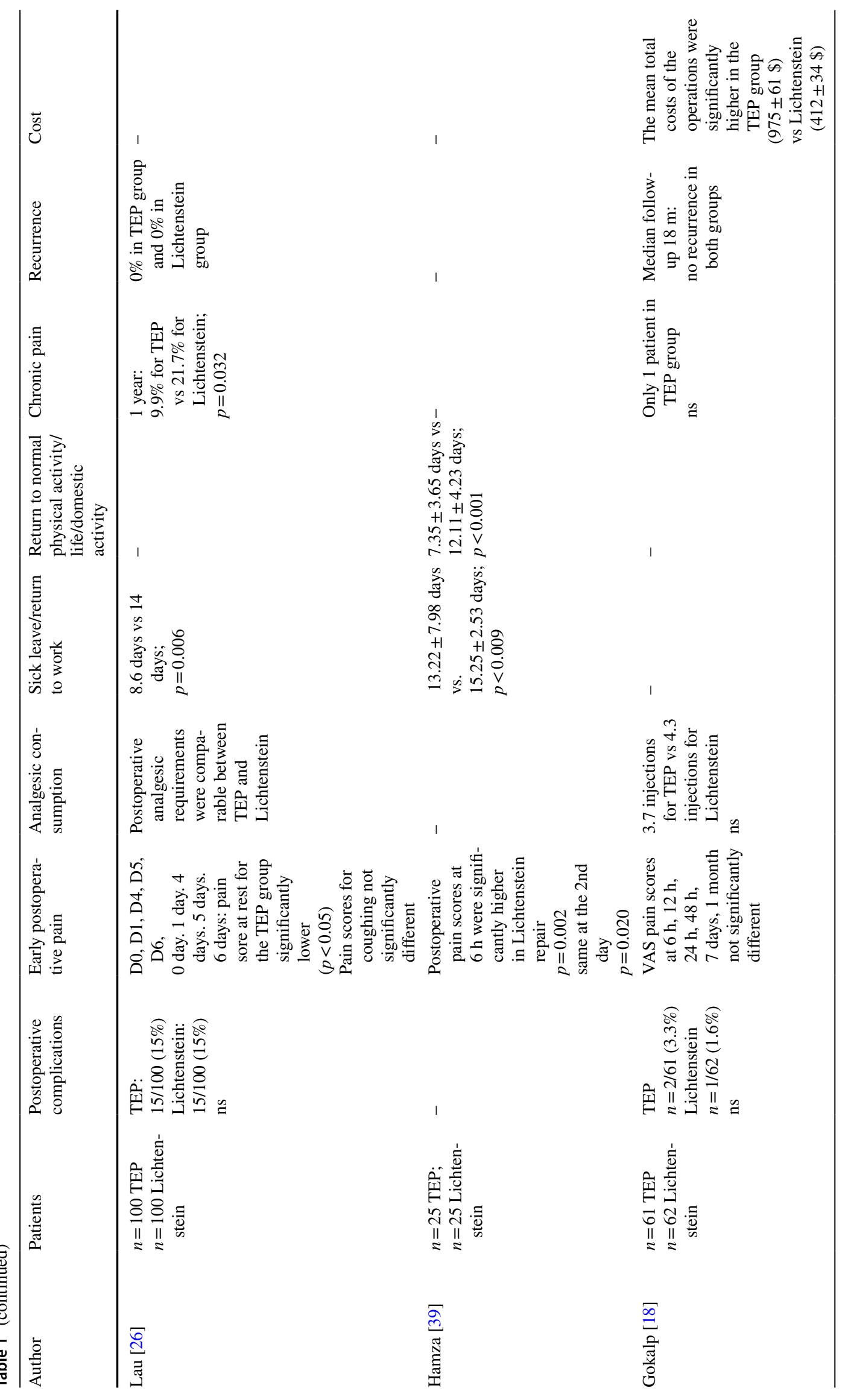


difference in the need for oral analgesics ( 8 vs 11 capsules) or in the duration of analgesia (4 vs 5 days). Return to normal life in the TEP group was significantly earlier (14 days vs 20 days; $p=0.02)$ as well as return to work (12 days vs 17 days; $p=0.01$ ).

In the study by Hamza et al. [39], which is a four-arm randomized trial comparing laparoscopic (TEP, TAPP) and open (Lichtenstein, preperitoneal) hernia repairs, 50 male patients with primary inguinal hernia were randomized to TEP $(n=25)$ or Lichtenstein $(n=25)$.

The operating time for TEP, at $77.4 \pm 43.21 \mathrm{~min}$, was significantly longer than for Lichtenstein repair at $34.21 \pm 23.5 \min (p<0.001)$. Postoperative pain on days 1 and 2 was significantly higher in patients with Lichtenstein repair $(p=0.002$ and 0.020 ). TEP operations were associated with significantly faster return to normal domestic activities $(7.53 \pm 3.65$ vs $12.11 \pm 4.23 ; p<0.001)$ and to work $(13.22 \pm 7.98$ vs $15.25 \pm 2.53 ; p<0.001)$.

In the study by Dahlstrand et al. [40], a total of 389 men with a unilateral primary inguinal hernia were randomized to either TEP under general anesthesia $(n=194)$ or Lichtenstein under local anesthesia $(n=195)$. One patient in the TEP group and four in the Lichtenstein group were excluded due to protocol violation. Men in the TEP group had less risk of pain affecting daily activities [6/191 vs 16/187; odds ratio (OR) 0.35 ; 95\% CI (0.13-0.91); $p=0.025]$. Pain prevented participation in sporting activities less frequently after TEP (4.2\% vs $15.5 \%$; OR $0.24 ; 95 \%$ CI $0.09-0.56 ; p<0.001$ ). Twenty-nine patients $(7.7 \%)$ reported sick leave exceeding 1 week due to groin pain, with no difference between the treatment groups. 6 weeks after surgery any pain in the operated groin was reported after TEP in $30.9 \%$ vs Lichtenstein in $46.5 \%(p=0.002)$ of cases.

The authors concluded that patients who underwent the TEP procedure suffered less pain 6 weeks after inguinal hernia repair than those who underwent Lichtenstein with local anesthesia. Groin pain after Lichtenstein with local anesthesia affected the patients' ability to perform strenuous activities such as sports more than TEP patients.

In the study by Dhankhar et al. [41], a total of 59 men with primary unilateral inguinal hernia were analyzed at the end of the study, 29 in the TEP under general anesthesia group and 30 in the Lichtenstein under local anesthesia group. The operating time $(75.93 \pm 13.68$ vs $64.77 \pm 12.66$; $p=0.002)$ and total operating room time $(102.66 \pm 15.676$ vs $72.64 \pm 12.25 \mathrm{~min} ; p<0.001)$ were significantly longer in the TEP group. There was no significant difference in the postoperative complication rate (TEP $13.8 \%$ vs Lichtenstein $20 \% ; \mathrm{p}=\mathrm{ns}$ ). Postoperative pain scores in the TEP group were lower than the scores in the Lichtenstein group, but the difference was not statistically significant. There was significantly more use of analgesics and higher C-reactive protein levels in the Lichtenstein group. Quality of life and patient satisfaction were similar in both groups. The authors concluded that Lichtenstein under local anesthesia was as good as TEP under general anesthesia.

In the study by Gokalp et al. [18], 123 men with a primary unilateral inguinal hernia were treated with TEP $(n=61)$ or Lichtenstein $(n=62)$ inguinal hernia repair. The patients were followed up for a median of 18 months. In terms of postoperative pain, analgesic requirements, complications, hospital stay and duration of limitation of normal daily activities, there was no significant differences between the two groups. Operating time for TEP was 16 min longer than for Lichtenstein open tension-free technique. Return to work was shorter in patients with TEP.

Only four out of seven RCTs comparing TEP vs Lichtenstein for unilateral primary inguinal hernia in male patients reported the recurrence and chronic pain rates.

In the study by Heikkinen et al. [19], there were no recurrences in either group after a median follow-up of 10 months.

In the Lau study [26], none of the patients was found to have clinical recurrence at the 1-year follow-up assessment. The incidence of chronic pain after open repair at 1 year $(21.7 \%)$ was significantly higher for Lichtenstein than for TEP $(9.9 \%)(p=0.032)$.

In the study by Eklund et al. [31] at a median of 5.1 (4.4-9.1) years after operation, 1275/1353 (94.2\%) patients completed follow-up. The cumulative recurrence rate at 5 years was $3.5 \%(n=21)$ in the TEP group and $1.2 \%$ $(n=7)$ in the Lichtenstein group $(p=0.008)$. There was wide variability in the incidence of recurrence between different surgeons and hospitals for the TEP method. The 5-year recurrence rate ranged from $0 \%$ to $32 \%(0 / 55-7 / 22)$ for the individual surgeons and from $0 \%$ to $13.5 \%(0 / 101-7 / 52)$ for the different hospitals. This was not the case for the Lichtenstein repair, where the corresponding rates ranged from $0 \%$ to $4.3 \%(0 / 46-1 / 23)$ and from $0 \%$ to $2.4 \%(0 / 64-2 / 86)$, respectively. Three out of 22 surgeons in the TEP group were responsible for 57\% (12/21) of all recurrences, one of them for 33\% (7/21). This surgeon operated on 25 patients, 22 of whom completed follow-up. His results diverged greatly from those of the other surgeons in the TEP group when tested for heterogeneity $(p<0.001)$. If this surgeon is excluded from the calculation, the cumulative recurrence rate in the TEP group would be $2.4 \%$, and the difference in recurrence rate between the groups would be nonsignificant $(p=0.109)$.

The total incidence of chronic pain in the study by Eklund et al. [32] was 11.0 versus $21.7 \%$ at 1 year, 11.0 versus $24.8 \%$ at 2 years, 9.9 versus $20.2 \%$ at 3 years and 9.4 versus $18.8 \%$ at 5 years in the TEP and Lichtenstein groups, respectively $(p<0.001)$.

In the study by Gokalp et al. [18], only one case experienced persistent discomforting pain during the follow-up 
period. This patient in the TEP group developed genitofemoral neuralgia. In this patient, pain persisted longer than 6 months and disappeared after applying a nerve bloc three times with absolute alcohol. There has been no recurrence in either group after a median follow-up of 18 months.

Only in two studies was cost analysis performed. In the study by Gokalp et al. [18], the mean total costs of the operations were significantly higher in the TEP group $(975 \pm 61$ US dollars) than the Lichtenstein group $(412 \pm 34$ US dollars).

In the study by Eklund et al. [38], the total hospital costs for the index operation was $€ 710.6$ higher for TEP repair $(p<0.001)$. Including costs associated with recurrences and complications, this difference increased to $€ 795.1$ $(p<0.001)$. Taking community costs into account, the difference decreased by $€ 503.1-292.0(p=0.024)$.

In summary, no differences were observed in the intraor postoperative complications following primary unilateral inguinal hernia repair in male patients between the TEP and Lichtenstein technique. Clear advantages were observed for the TEP technique in terms of early postoperative pain, analgesic consumption and return to normal daily activities and to work. When the surgeon had sufficient experience of the respective technique, i.e., after overcoming the learning curve, no significant difference was detected in the recurrence rate between the TEP and Lichtenstein operation. Likewise, chronic pain occurred significantly less often after TEP than after Lichtenstein operation. In the three RCTs with at least 100 patients in each arm, the operating time for TEP was either similar to or shorter than for Lichtenstein operation. The direct operative costs for TEP are higher than for the Lichtenstein operation. However, that difference decreases when all community costs are taken into account.

Further large RCTs are urgently needed to compare TEP versus Lichtenstein for primary unilateral inguinal hernia in male patients. It must be ensured that, by carefully selecting the participating surgeons, the learning curve has been overcome for the respective surgical technique (Table 2).

\section{Comparison of TEP vs Lichtenstein in registry studies}

In a multivariable analysis of data from the Herniamed Registry, 10,555 Lichtenstein operations were compared with 6833 TEP operations for repair of elective primary unilateral inguinal hernia in male patients [43]. TEP was found to have

Table 2 Surgeons' experience and operating time

\begin{tabular}{|c|c|c|c|c|}
\hline Author & Patients & $\begin{array}{l}\text { Number of participating } \\
\text { surgeons }\end{array}$ & Experience & Operation time \\
\hline Eklund [17] & $\begin{array}{l}n=665 \text { TEP } \\
n=706 \text { Lichtenstein }\end{array}$ & $\begin{array}{l}\text { TEP: } \\
11 \text { hospitals, } 48 \text { surgeon } \\
22 \text { TEP group } \\
26 \text { Lichtenstein group }\end{array}$ & $\begin{array}{l}\geq 25 \text { TEP No surgeon did } \\
\text { both techniques }\end{array}$ & $\begin{array}{l}\text { Median: } \\
55(12-180) \text { min TEP; } \\
55(20-145) \text { min Lichtenstein; } \\
\text { ns }\end{array}$ \\
\hline Lau [26] & $\begin{array}{l}n=100 \text { TEP; } \\
n=100 \text { Lichtenstein }\end{array}$ & - & $\begin{array}{l}\text { Specialist surgeons who had } \\
\text { experience exceeding } 200 \\
\text { corresponding procedures }\end{array}$ & $\begin{array}{l}50 \pm 13,2 \mathrm{~min} \text { for TEP vs } \\
58 \pm 17,6 \text { min for Lichten- } \\
\text { stein; } \\
p<0.001\end{array}$ \\
\hline Heikkinen [19] & $\begin{array}{l}n=22 \text { TEP } \\
n=23 \text { Lichtenstein } \\
\text { All employed }\end{array}$ & 1 Surgical resident & $\begin{array}{l}\text { Special interesting and fair } \\
\text { experience with open and } \\
\text { laparoscopic hernia surgery }\end{array}$ & $\begin{array}{l}\text { Median: } \\
67,5[72-88] \text { min, range } 40-88 \\
\text { min for TEP vs } \\
53 \text { min, range } 42-78 \text { min for } \\
\text { Lichtenstein; } \\
p=0.001\end{array}$ \\
\hline Hamza [39] & $\begin{array}{l}n=25 \text { TEP; } n=25 \text { Lichten- } \\
\text { stein }\end{array}$ & $\begin{array}{l}1 \text { Surgeon performing all } \\
\text { operation in a four-arm trial } \\
\text { (TEP, TAPP, Lichtenstein, } \\
\text { open preperitoneal }\end{array}$ & - & $\begin{array}{l}77.4 \pm 43.21 \mathrm{~min} \text { for TEP vs } \\
34.21 \pm 23.5 \text { for Lichtenstein; } \\
p<0.001\end{array}$ \\
\hline Dahlstrand [40] & $\begin{array}{l}n=194 \text { TEP; } n=195 \text { Lichten- } \\
\text { stein }\end{array}$ & $\begin{array}{l}2 \text { Hospitals, } \\
4 \text { Surgeons }\end{array}$ & $\begin{array}{l}\text { All surgeons were experi- } \\
\text { enced in open and laparo- } \\
\text { scopic procedures and did } \\
\text { not have a preference for } \\
\text { either technique }\end{array}$ & $\begin{array}{l}\text { Median } 60 \mathrm{~min} \text {, range } 50-72 \\
\text { min for TEP, } 70 \text { min, range } \\
60-80 \text { min for Lichtenstein; } \\
p<0.001\end{array}$ \\
\hline Dhankhar [41] & $\begin{array}{l}n=29 \text { TEP; } n=30 \text { Lichten- } \\
\text { stein }\end{array}$ & 2 Hospitals & & $\begin{array}{l}75.93 \pm 13.68 \mathrm{~min} \text { for TEP vs } \\
64.77 \pm 12.66 \mathrm{~min} \text { for Lichten- } \\
\text { stein; } \\
p=0.002\end{array}$ \\
\hline Gokalp [18] & $\begin{array}{l}n=61 \text { TEP; } n=62 \text { Lichten- } \\
\text { stein }\end{array}$ & 1 Hospital & - & $\begin{array}{l}62 \pm 14 \text { min for TEP vs } \\
46 \pm 11 \text { min for Lichtenstein; } \\
p<0.01\end{array}$ \\
\hline
\end{tabular}


advantages with regard to the postoperative complication rate $(p<0.001)$, pain at rest $(p=0.011)$, and pain on exertion $(p<0.001)$ at 1 -year follow-up.

No advantages were noted for TEP in terms of the complication-related reoperation rate, recurrence rate or chronic pain rate requiring treatment at 1-year follow-up [43].

In another analysis of data from the Herniamed Registry, propensity score matching was performed to compare 12,564 TEP repairs with 12,564 Lichtenstein operations for patients with comparable characteristics [10].

That did not identify any systematic deviations between the two surgical techniques in terms of pain requiring treatment $[2.8 \%$ vs $2.6 \% ; p=0.282$; OR $1.090(0.934 ; 1.271)]$ or the recurrence rate $[0.8 \%$ vs $1.0 \% ; p=0.252 ; \mathrm{OR}=0.849$ $(0.645 ; 1.116)]$ at the 1 -year follow-up [10].

However, a systematic deviation was noted with regard to the disadvantages of Lichtenstein repair in postoperative complications ( $3.4 \%$ vs $1.7 \%$; $p<0.001)$, complicationrelated reoperation rate $(1.1 \%$ vs $0.8 \% ; p=0.008)$ and pain at rest $(5.2 \%$ vs $4.3 \% ; p=0.003)$ and on exertion $(10.6 \%$ vs $7.7 \% ; p<0.001$ ) [10]. On the other hand, a systematic deviation was identified with regard to the disadvantage of TEP in the intraoperative complications ( $0.9 \%$ vs $1.2 \% ; p=0.035)$.

Hence, the registry analyses demonstrated the disadvantages of TEP with regard to the intraoperative complications, but advantages for the postoperative complication rates and the complication-related reoperation rates [10]. At 1-year follow-up, TEP compared with Lichtenstein repair was found to have a lower rate of pain at rest and on exertion [10].

In summary, registry analyses identified the advantages of TEP compared with Lichtenstein operation for elective primary unilateral inguinal hernia repair in men with regard to the postoperative complications as well as complicationrelated reoperation and pain at rest and on exertion at the 1-year follow-up. TEP was found to have disadvantages with regard to the intraoperative complications.

\section{Comparison of TEP vs TAPP in meta-analyses and RCTs}

There are six systematic reviews and meta-analyses available for comparison of TEP with TAPP [44-49]. The systematic reviews by McCormack [44], Wake [45] and Bracale [46] did not include enough RCTs to permit direct comparison of TEP and TAPP.

The meta-analysis by Antoniou [47] included seven RCTs by Schrenk [50], Dedemadi [36], Butler [51], Pokorny [34], Hamza [39], Gong [52] and Krishna [53] with 516 patients. However, the patient population in the Schrenk and Pokorny $[34,50]$ RCTs included women, the RCT by Dedemadi [36] recurrences and the RCT by Krishna [53] bilateral inguinal hernias.
The remaining RCTs by Butler [51], Hamza [39] and Gong [52] directly compared TEP and TAPP for primary unilateral inguinal hernia in men (Table 3 ).

Butler [51] reported minimally higher costs for TEP in comparison with TAPP. No difference was identified for postoperative pain or analgesic consumption. The average number of lost work days in both groups was 12. Likewise, there was no difference in the recurrence rate.

The RCT by Hamza [39] did not note any difference in the operating time, postoperative complications or postoperative pain between TEP and TAPP, nor was there any difference in the time to return to normal activities and work. Similarly, comparable recurrence rates were identified.

Likewise, on comparing TEP and TAPP for primary unilateral inguinal hernia in men, the RCT by Gong [52] did not find any difference in the operating time, postoperative complication rate, hospital stay or postoperative pain. The time to return to normal activities was also comparable.

The meta-analysis by Wei [48] then featured three further RCTs with a total of 1047 patients by Zhu [54], Bansal [55] and Wang [56]. The RCT by Zhu [54] investigated the effects of $\mathrm{CO}_{2}$ insufflation on the circulatory system and lung function and found no difference between TEP and TAPP. The RCT by Bansal [55] included a high proportion of bilateral inguinal hernias, while the surgical patient group reported on in the RCT by Wang [56] included women.

The most recent meta-analysis for comparison of TEP with TAPP by Chen [49] with 1519 randomized patients included six further RCTs by Ciftci [57], Mesci [58], Sharma [59], Günal [60], Bansal [61] and Jeelani [62]. But five of these six additional RCTs included women, recurrences or bilateral inguinal hernias $[57-59,61,62]$ and therefore had to be excluded from the present analysis. The RCT by Günal [60] did not identify any clinically relevant difference between TEP and TAPP in the postoperative complications, postoperative pain or recurrence rate.

In summary, it can be stated that only very few RCTs with a small sample size are available for comparison of TEP and TAPP for elective primary unilateral inguinal hernia repair in men. Those RCTs available did not find any differences for the outcome parameters postoperative complications, postoperative pain, analgesic consumption or return to normal activities and work. More data are urgently needed for comparison of TEP and TAPP for elective primary unilateral inguinal hernia repair in men.

\section{Comparison of TEP and TAPP in registry studies}

In a registry-based, propensity score-matched comparison of 14,426 TEP with 14,426 TAPP elective primary unilateral inguinal hernia repairs in men, no difference was seen in the intraoperative complications $(1.1 \%$ vs $1.1 \% ; p=0.911)$, complication-related reoperation $(0.9 \%$ vs $0.8 \% ; p=0.309)$, 
Table 3 Outcome of RCTs comparing TEP repair of primary unilateral inguinal hernia in men vs TAPP repair

\begin{tabular}{|c|c|c|c|c|c|c|c|c|c|}
\hline Author & Patients & $\begin{array}{l}\text { Postopera- } \\
\text { tive compli- } \\
\text { cations }\end{array}$ & $\begin{array}{l}\text { Early post- } \\
\text { operative } \\
\text { pain }\end{array}$ & $\begin{array}{l}\text { Analgesic } \\
\text { consump- } \\
\text { tion }\end{array}$ & $\begin{array}{l}\text { Sick leave/ } \\
\text { return to } \\
\text { work }\end{array}$ & $\begin{array}{l}\text { Return to } \\
\text { normal physi- } \\
\text { cal activity/ } \\
\text { life/domestic } \\
\text { activity }\end{array}$ & $\begin{array}{l}\text { Chronic } \\
\text { pain }\end{array}$ & Recurrence & Cost \\
\hline Butler [51] & $\begin{array}{l}n=22 \text { TEP } \\
n=22 \\
\text { TAPP }\end{array}$ & - & $\begin{array}{l}\text { No signifi- } \\
\text { cant dif- } \\
\text { ference }\end{array}$ & $\begin{array}{l}\text { No signifi- } \\
\text { cant dif- } \\
\text { ference }\end{array}$ & $\begin{array}{l}\text { Average } \\
\text { number } \\
12 \text { days vs } \\
12 \text { days } \\
\text { (ns) }\end{array}$ & - & - & $\begin{array}{l}4.5 \% \text { for } \\
\text { TEP and } \\
\text { TAPP }(n s)\end{array}$ & $\begin{array}{l}\text { Minimal } \\
\text { higher }(\$ \\
\text { 125) for } \\
\text { TEP }\end{array}$ \\
\hline Hamza [39] & $\begin{array}{l}n=25 \text { TEP; } \\
n=25 \\
\text { TAPP }\end{array}$ & $\begin{array}{l}\text { No signifi- } \\
\text { cant dif- } \\
\text { ference }\end{array}$ & $\begin{array}{l}\text { Pain scores } \\
6 \text { h post- } \\
\text { operative: } \\
\text { TEP } \\
4.8 \pm 2.33 \\
\text { TAPP } \\
5.8 \pm 1.6 \\
\text { (ns) }\end{array}$ & - & $\begin{array}{l}\text { TEP mean } \\
13.2 \text { days, } \\
\text { TAPP mean } \\
14.9 \text { days } \\
(\mathrm{ns})\end{array}$ & $\begin{array}{l}\text { TEP mean } \\
7.5 \text { days, } \\
\text { TAPP mean } \\
9.8 \text { days } \\
\text { (ns) }\end{array}$ & - & $\begin{array}{l}4.0 \% \text { for } \\
\text { TEP and } \\
\text { TAPP (ns) }\end{array}$ & - \\
\hline Gong [52] & $\begin{array}{l}n=52 \text { TEP } \\
n=50 \\
\text { TAPP }\end{array}$ & $\begin{array}{l}\text { TEP } 13.5 \% \\
\text { TAPP } \\
12.0 \% \\
(\mathrm{~ns})\end{array}$ & $\begin{array}{l}\text { TEP pain } \\
\text { score } 24 \mathrm{~h} \\
\text { postop- } \\
\text { erative } \\
1.7 \pm 0.7 \\
\text { TAPP pain } \\
\text { score } 24 \mathrm{~h} \\
\text { postop- } \\
\text { erative } \\
1.6 \pm 0.7 \\
\text { (ns) } \\
\text { TEP pain } \\
\text { score } \\
1 \text { week } \\
\text { postop- } \\
\text { erative } \\
0.3 \pm 0.5 \\
\text { TAPP pain } \\
\text { score } \\
1 \text { week } \\
\text { postop- } \\
\text { erative } \\
0.3 \pm 0.7 \\
\text { (ns) }\end{array}$ & - & - & $\begin{array}{l}\text { TEP } \\
6.6 \pm 1.5 \text { days } \\
\text { TAPP } \\
6.6 \pm 1.7 \text { days } \\
(\mathrm{ns})\end{array}$ & - & - & $\begin{array}{l}\text { No significant } \\
\text { difference } \\
\text { between } \\
\text { TEP and } \\
\text { TAPP }\end{array}$ \\
\hline Günal [60] & $\begin{array}{l}n=40 \text { TEP } \\
n=39 \\
\text { TAPP }\end{array}$ & $\begin{array}{l}\text { TEP } 7.5 \% \\
\text { TAPP } 5.1 \% \\
\text { (ns) }\end{array}$ & $\begin{array}{l}\text { Pain scores } \\
6 \text { h postop- } \\
\text { erative: } \\
\text { TEP } \\
5.5 \pm 1.2 \\
\text { TAPP } \\
6 \pm 1.4 \\
48 \text { h postop- } \\
\text { erative: } \\
\text { TEP } \\
3.3 \pm 1.2 \\
\text { TAPP } \\
3.25 \pm 1\end{array}$ & - & - & - & - & $\begin{array}{l}\text { TEP } 0 \% \\
\text { TAPP } 2.6 \% \\
(n s)\end{array}$ & - \\
\hline
\end{tabular}

recurrence rate $(1.0 \%$ vs $1.0 \% ; p=0.907)$ at 1 -year follow up, pain at rest $(4.8 \%$ vs $5.3 \% ; p=0.907)$ at 1 -year followup, pain on exertion ( $8.6 \%$ vs $8.4 \% ; p=0.613)$ at 1 -year follow-up or pain requiring treatment $(2.8 \%$ vs $2.7 \% ; p=0.831)$ at 1-year follow-up [10]. Only for the postoperative complications $(3.0 \%$ vs $1.7 \%$; $p<0.001)$ was a significant deviation noted to the disadvantage of TAPP [10]. The higher rate of postoperative complications was due to the higher seroma 
rate in TAPP $(2.1 \%$ vs $0.5 \% ; p<0.001)$. But the bleeding rate was higher in TEP at $0.8 \%$ vs $1.1 \%(p=0.008)$.

In summary, a large registry analysis did not find any relevant difference between TAPP vs TEP with regard to the outcome of elective primary unilateral hernia repair in men. Only a higher seroma rate in TAPP led to a higher postoperative complication rate to the disadvantage of TAPP. Since that did not result in a higher complication-related reoperation rate, TEP and TAPP can be used with comparable safety.

\section{Fixation vs non-fixation of the mesh in TEP}

In three meta-analyses, TEP outcomes were compared with regard to mesh fixation vs non-fixation [63-65]. All metaanalyses concluded that mesh fixation was not needed in TEP. In particular, non-fixation of the mesh was not associated with a higher recurrence rate.

The meta-analysis by Tam [63] included five RCTs by Ferzli [66], Koch [67], Moreno-Egea [68], Parschad [69] and Taylor [70] and one case-control study by Lau [71] . However, the patient collectives of all studies included women $[68,69,71]$, recurrences $[67,68,71]$ or bilateral inguinal hernias [66-70].

The meta-analysis by Teng [64] had only one additional study that did not report any further details of the patient collective [72].

Another RCT by Garg [73] was then included in the metaanalysis by Sajid [65], but that patient group also included bilateral inguinal hernias.

Hence, there is no RCT that compared mesh fixation vs non-fixation only for elective primary unilateral inguinal hernia repair in men.

A study based on data from the Swedish Hernia Registry identified for 1110 primary inguinal hernia repairs in men in TEP technique a low frequency of chronic pain and recurrent operations, with no difference between permanent fixation and non-permanent fixation of the mesh [74]. But that registry study, too, included a large proportion of patients with bilateral inguinal hernia. However, since the recurrence risk is higher for bilateral inguinal hernias and recurrent inguinal hernias than for primary unilateral inguinal hernia in men, the findings can be reliably extrapolated to the latter. Nonetheless, corresponding studies should also be conducted to explore that key question.

In summary, it can be stated that despite the lack of studies, it can be assumed that for primary unilateral inguinal hernia in men mesh fixation is not needed in TEP.

\section{Lightweight vs heavyweight mesh in TEP}

Two meta-analyses are available for comparison of lightweight vs heavyweight meshes for laparoendoscopic inguinal hernia repair [75, 76]. The meta-analysis by Currie [75] included six RCTs in which the TEP technique had been used. These were RCTs carried out by Bringman [77], Heikkinen [78], Agarwal [79], Chowbey [80], Chui [81] and Peeters [82]. The authors of the meta-analysis concluded that the choice of mesh did not impact the recurrence rate or the chronic pain rate [75]. However, the RCTs reporting on the TEP technique also included patients with recurrent inguinal hernias [78] or bilateral inguinal hernias [77, 79-82]. The same studies reporting on the TEP technique were also included in another meta-analysis by Sajid [76-82]. The conclusion drawn from that meta-analysis was that on comparing lightweight vs heavyweight meshes in TEP technique, the recurrence rate did not differ but lightweight meshes resulted in a lower rate of chronic pain [76]. Based on those RCTs included in the meta-analyses, the finding cannot be applied to primary unilateral inguinal hernia in men.

Following those two meta-analyses, details of a further RCT comparing lightweight vs heavyweight meshes in 950 TEP operations for primary unilateral inguinal hernia in men were published [83]. At the 2-year follow-up a recurrence rate of $0.8 \%$ was identified for the heavyweight and of $2.7 \%$ for the lightweight meshes ( $p=0.03$ ) [83]. At postoperative year 1 , the relevant pain rate was higher in the lightweight mesh group ( $2.9 \%$ vs $0.7 \% ; p=0.01)$ [83]. 5 years after TEP repair, the recurrence rate for the lightweight mesh continued to be significantly higher ( $3.8 \%$ vs $1.1 \% ; p=0.01)$ [84]. The authors concluded that the use of lightweight meshes in TEP did not bestow any advantages [83, 84].

The findings of that large RCT were then confirmed once again by an analysis of data from the Swedish Hernia Registry [85]. That registry analysis of data on 13,839 TEP repairs identified a significantly higher recurrence rate for lightweight meshes $(4.0 \%$ vs $3.2 \% ; p<0.001)$ [85]. The difference persisted even after exclusion of bilateral inguinal hernias and recurrences [85].

In summary, it can be stated that the use of a heavyweight mesh for TEP repair of a primary unilateral inguinal hernia in men results in a lower recurrence rate without increasing the chronic pain rate.

\section{Effect of extraperitoneal bupivacaine analgesia in TEP}

A meta-analysis of RCTs investigating the effect of extraperitoneal bupivacaine analgesia included eight studies with a total of 373 patients [86]. In all RCTs, TEP repair with extraperitoneal bupivacaine analgesia vs placebo was compared [87-94]. The meta-analysis did not demonstrate any advantages for extraperitoneal bupivacaine analgesia [86]. Only three of the eight included RCTs investigated the effect of bupivacaine in primary unilateral inguinal hernia repair in men [92-94]. Likewise, these three RCTs did not identify 
any advantage for administration of extraperitoneal analgesia on concluding TEP repair.

In summary, it can thus be noted that extraperitoneal bupivacaine analgesia does not have any advantages in TEP.

\section{Drainage after TEP}

In one RCT with 90 patients, TEP repair of primary unilateral inguinal hernia with drainage vs non-drainage was compared [95]. Drainage was found to be associated with a significant reduction in the seroma rate up to postoperative day 6 [95]. The authors concluded that drainage of the extraperitoneal space in TEP reduced the seroma rate in the early postoperative phase [95].

\section{Convalescence after TEP}

A systematic review then demonstrated that the risk factors fixation vs non-fixation, heavyweight vs lightweight mesh and peritoneal bupivacaine analgesia vs saline had no effect on the convalescence of patients after primary unilateral inguinal hernia repair in men with the TEP technique [96].

\section{Influencing factors for chronic pain in TEP}

A systematic review of early pain after laparoendoscopic inguinal hernia repair found that TEP was associated with the greatest pain intensity on postoperative day 1 [97], with the greatest pain intensity observed in young men [97]. The rate of moderate to severe chronic pain identified in a systematic review after laparoendoscopic repair was 1.1\% [98].

An analysis of data for 57,999 male patients from the Herniamed Registry who underwent elective primary unilateral inguinal hernia repair revealed that small inguinal hernia, independently of the surgical technique, was associated with a significantly higher risk of chronic pain requiring treatment [99]. Comparison of EHS I $(<1.5 \mathrm{~cm})$ vs EHS II $(\geq 1.5-3 \mathrm{~cm})$ [OR $1.482(1.212-1.812) ; p<0.001]$ and EHS I $(<1.5 \mathrm{~cm})$ vs EHS III ( $>3 \mathrm{~cm})$ [OR 1.582 (1.199-2.088); $p=0.001]$ in TEP demonstrated that small hernia presented a significantly higher risk for development of chronic pain requiring treatment [99].

Similarly, a higher probability of chronic inguinal pain requiring treatment in relation to patient age $(<55$ years vs $\geq 55$ years) was identified once again in the registry analysis [OR $2.021(1.806-2.201) ; p<0.001$ ] [99]. Other negative influencing factors were preoperative pain, higher BMI, postoperative complications, higher ASA score and risk factors [99].

\section{Male infertility following TEP}

One systematic review investigated the influence of TEP on male infertility [100]. The analysis included 108 TEP repairs reported on in the studies by Skawran [101] and Peeters [102]. In both studies bilateral inguinal hernias were repaired with the TEP technique. Likewise, in the study protocol by Schouten on male infertility after TEP inguinal hernia repair, only bilateral inguinal hernias were included [103].

Likewise, another systematic review by Dong [104] featured the studies by Skawran [101], Peeters [102] and the study protocol by Schouten, in addition to the studies by Lal [105], Singh [106], Akbulut [107] and Peeters [82]. But these additional studies, too, included bilateral inguinal hernias.

From that systematic review, the authors concluded that inguinal hernia repair with mesh in laparoendoscopic technique had no significant effect on male fertility [104]. Although all the included studies featured bilateral inguinal hernias, it can be assumed that the conclusion drawn can also be applied to elective primary unilateral inguinal hernia repair in male patients, since the extent of dissection is less in primary unilateral inguinal hernia than in bilateral repair.

\section{Surgeon volume in the outcome of TEP}

Systematic reviews have demonstrated strong evidence of an association between higher volumes and better outcome in surgery [108].

A study of data from the Herniamed Registry identified for primary unilateral inguinal hernia repair in men in laparoendoscopic technique significant differences in relation to the annual surgeon volume [109]. Multivariable analysis revealed that patients operated on by surgeons with an annual surgeon volume of $\geq 25$ operations had a significantly lower risk of recurrence $[<25$ vs $\geq 25$ : OR 1.494 $(1.056-2.115) ; p=0.023]$ and pain on exertion $[<25$ vs $\geq 25$ : OR $1.191(1.062-1.337) ; p=0.003$ ] at the 1-year follow-up [109].

That finding was confirmed by a further study for surgeons with $>30$ TEP operations per year, albeit that study included a very large proportion of bilateral procedures [110].

Likewise, the study by Aikoye [111], which also included bilateral inguinal hernias, confirmed the relationship between surgical volume and outcome in TEP inguinal hernia repair.

\section{Personal experience with the TEP}

As the chairman responsible for a Department of General Surgery, first in Hanover and then in Berlin, the author has 20 years' experience of routine inguinal hernia repair in 
TEP technique [112]. During that period, the technique was standardized in accordance with evidence-based data [3, 4, 112-114]. The findings from the time in Hanover have been reported in several publications [115-117]. In a consecutive series of 5203 TEP repairs in 3868 patients with inguinal hernias (uni- and bilateral in men and women, recurrences), the intraoperative complication rate was $0.9 \%$, the postoperative complication rate $3.4 \%$, the complication-related reoperation rate $2.8 \%$ and the recurrence rate $0.6 \%$ [113].

Between 2010 and 2018, 3365 hernia patients were treated in the Certified Hernia Center, Department of General Surgery, Vivantes Hospital Berlin, and their data entered into the Herniamed Hernia Registry. These related to 1679 patients with 2166 inguinal hernia repairs, 761 incisional hernias, 375 epigastric hernias, 283 umbilical hernias, 239 hiatal hernias and 28 parastomal hernias. Of the 2166 inguinal hernia repairs, 1000 were performed or assisted with TAPP technique by two senior physicians and 834 with TEP technique, which were all carried out by the author himself or at which he assisted, 291 with Lichtenstein and 41 with other techniques.

Of the 834 TEP repairs, only 196 (23.5\%) involved elective primary unilateral inguinal hernia repair in men. No intraoperative complications occurred in that subgroup of male patients with unilateral inguinal hernia. In the postoperative phase, there were three cases $(1.5 \%)$ of secondary bleeding in patients continuing to receive treatment with platelet aggregation inhibitors, two cases of seroma $(1.0 \%)$ and two (1.0\%) of impaired wound healing at a trocar puncture site. The complication-related reoperation rate was $1.0 \%$. This was because of secondary bleeding. At the 1-year follow-up, no patient suffered from chronic pain requiring treatment and there were no recurrences. Pain at rest was reported by $2.0 \%$ of patients and pain on exertion by $7.7 \%$. Hence, through standardization of the TEP technique, it is possible to achieve very good perioperative outcomes and low chronic pain and recurrence rates. As the same is proven for the TAPP technique, laparoendoscopic repair is the standard procedure for elective primary unilateral inguinal hernia in men in our hospital.

\section{Discussion}

In all guidelines TEP and TAPP as well as the Lichtenstein operation as a mesh procedure are recommended for repair of inguinal hernia [1-6]. However, the new international guidelines for groin hernia management state that there is no one technique that is suited to all inguinal hernia findings [6]. Rather, it is recommended that a tailored approach should be used based on the surgeon's expertise, the local/ national resources and on patient- and hernia-related factors. Accordingly, in line with the tailored approach concept based on patient- and hernia-related factors, a distinction must be made between primary unilateral inguinal hernia in men and in women, primary bilateral inguinal hernia in men and in women, primary scrotal hernia, inguinal hernia after pelvic and lower abdominal procedures, inguinal hernia in patients with severe cardiopulmonary risk factors, recurrent inguinal hernias and incarcerated inguinal hernias [6-8]. These subgroups from the entire collective of inguinal hernias should in the future be scientifically viewed as separate entities. The reason for this is that there are significant differences in the outcomes of inguinal hernia surgery between the subgroups $[6,9,11,12]$. Elective primary unilateral inguinal hernia in men accounting for about $50 \%$ of inguinal hernias is the largest subgroup, which explains why their repair constitutes the standard procedure in inguinal hernia surgery $[6-8,10]$. The proportion of primary unilateral inguinal hernias in women is around $10 \%$, recurrent hernias likewise account for $10 \%$ and bilateral inguinal hernias for around 20\% [6-12].

A rigorous scientific reduction to subgroups from the entire collective of inguinal hernias not only results in exclusion of several RCTs, but also in a re-evaluation of systematic reviews and meta-analyses. This considerably reduces the total number of studies available for answering key scientific questions. But this would mean that the remaining studies would enable more precise statements to be issued for a specific subgroup of inguinal hernias.

In the present analysis of the outcome of elective primary unilateral inguinal hernia repair in men using TEP technique, ten publications [17-19, 26, 31, 32, 38-41] from seven RCTs demonstrated advantages for TEP in comparison with open Lichtenstein repair. Clear advantages have been observed for the TEP technique in terms of early postoperative pain, analgesic consumption and return to normal daily activities and to work. Likewise, chronic pain occurred significantly less often after TEP than after Lichtenstein repair. No difference was found in the postoperative complications or recurrence rates.

Unlike in the RCTs, registry analyses identified for Lichtenstein repair a significantly higher postoperative complication rate and complication-related reoperation rate in comparison with TEP. This could also be because of no patient selection in the registries compared with the rigorous patient selection in the RCTs. Risk patients are not excluded from registries. Similarly, selection of the participating surgeons is less strict in registries than in RCTs. As regards chronic pain, advantages were identified for TEP compared with Lichtenstein repair in the available RCTs and registry analyses. An overview of the available findings for TEP vs Lichtenstein for elective primary unilateral inguinal hernia in men demonstrated advantages for TEP with regard to postoperative complications, complication-related reoperations, early postoperative pain, return to normal activity and 
work as well as chronic pain. No difference was found in the recurrence rate. A higher intraoperative complication rate may be expected with TEP.

Comparison of TEP vs TAPP did not find any relevant difference $[10,39,51,52]$ in either the RCTs or registry data for TEP vs TAPP in primary unilateral inguinal hernia repair in men. Only in one registry analysis [10] was a higher seroma rate identified for TAPP, leading to a higher postoperative complication rate but without increasing the complication-related reoperation rate. This is thought to have been attributable to the failure to reduce the medial hernia defect [6].

There are no RCTs or registry analyses available for mesh fixation vs non-fixation in TEP for elective primary unilateral inguinal hernia repair in men. But from the findings available for bilateral inguinal hernias it can be concluded that fixation can be dispensed with in elective primary unilateral inguinal hernia repair in men [63-74].

Surprisingly, comparison of lightweight vs heavyweight meshes for elective primary unilateral inguinal hernia repair in men demonstrated an advantage for the heavyweight meshes in terms of a lower recurrence rate [75-85], with no attendant increase in the chronic pain rate.

Extraperitoneal bupivacaine analgesia vs placebo did not identify any positive effect following elective primary unilateral inguinal hernia TEP repair and should therefore not be administered [86-94].

None of the risk factors, fixation vs non-fixation, lightweight vs heavyweight mesh or preperitoneal bupivacaine analgesia impacted convalescence after elective primary unilateral inguinal hernia repair in men using TEP technique [96].

For smaller defects, an increased risk of chronic inguinal pain was identified, independently of the surgical technique, following elective primary unilateral inguinal hernia repair in men [99]. Other influencing factors were age $<55$, preoperative pain, higher BMI, postoperative complications, high ASA score and risk factors [99].

While there are no studies on male infertility following elective primary unilateral inguinal hernia TEP repair in men, as these are available only for patients operated on for bilateral hernias, the findings for bilateral TEP can be extrapolated to unilateral repair since this involves less dissection [82, 101-107].

An annual surgeon volume von $\geq 25$ TEP operations for elective primary unilateral inguinal hernia repair in men results in a significant reduction in the risk of recurrence and pain on exertion [109].

In summary, it can be stated that in the future scientific studies aimed at comparison of different surgical techniques and identification of factors influencing the outcome should focus on, as far as possible, homogeneous subgroups of inguinal hernias. The subgroup of elective primary unilateral inguinal hernia in men is best suited to that purpose, since it is the most common type of inguinal hernia, accounting for a proportion of around $50 \%$ of the entire collective of inguinal hernias and constituting the standard procedure in inguinal hernia surgery. The present analysis of TEP for this subgroup demonstrates advantages compared with open Lichtenstein repair and comparable findings with the TAPP. Mesh fixation is not needed in TEP, but heavyweight meshes result in a lower recurrence rate. Extraperitoneal bupivacaine analgesia does not demonstrate any advantages for postoperative pain, but drainage appears to reduce the seroma rate. Mesh non-fixation, the use of a heavyweight mesh or preperitoneal bupivacaine analgesia do not have a positive effect on convalescence. The risk of chronic pain following TEP is increased for smaller defects, younger patients, preoperative pain, higher BMI, postoperative complications, higher ASA score and risk factors. TEP was not found to have a negative effect on male infertility. An annual surgeon volume of $\geq 25$ TEP repairs results in lower recurrence and pain on exertion rates.

\section{Compliance with ethical standard}

Conflict of interest The author declares that he has no conflict of interest.

Ethical approval An ethics vote was not necessary for this study.

Human and animal rights The author confirms that no experiments with humans or animals have been carried out.

Informed consent Informed consent was not required for this study.

Open Access This article is distributed under the terms of the Creative Commons Attribution 4.0 International License (http://creativeco mmons.org/licenses/by/4.0/), which permits unrestricted use, distribution, and reproduction in any medium, provided you give appropriate credit to the original author(s) and the source, provide a link to the Creative Commons license, and indicate if changes were made.

\section{References}

1. Simons MP, Aufenacker T, Bay-Nielsen M, Bouillot JL, Campanelli G, Conze J, de Lange D, Fortelny R, Heikkinen T, Kingsnorth A, Kukleta J, Morales-Conde S, Nordin P, Schumpelick V, Smedberg S, Smietanski M, Weber G, Miserez M (2009) European Hernia Society guidelines on the treatment of inguinal hernia in adult patients. Hernia 13:343-403. https://doi.org/10.1007/ s10029-009-0529-7

2. Miserez M, Peeters E, Aufenacker T, Bouillot JL, Campanelli G, Conze J, Fortelny R, Heikkinen T, Jorgensen LN, Kukleta J, Morales-Conde S, Nordin P, Schumpelick V, Smedberg S, Smietanski M, Weber G, Simons MP (2014) Update with level 1 studies of the European Hernia Society guidelines on the treatment of inguinal hernia in adult patients. Hernia 18:151-163. https://doi.org/10.1007/s10029-014-1236-6 
3. Bittner R, Arregui ME, Bisgaard T, Dudai M, Ferzli GS, Fitzgibbons RJ, Fortelny RH, Klinge U, Kockerling F, Kuhry E, Kukleta J, Lomanto D, Misra MC, Montgomery A, Reinpold W, MoralesConde S, Rosenberg J, Sauerland S, Schug-Pass C, Singh K, Timoney M, Weyhe D, Chowbey P (2011) Guidelines for laparoscopic (TAPP) and endoscopic (TEP) treatment of inguinal hernia [International Endohernia Society (IEHS)]. Surg Endosc 25:2773-2843. https://doi.org/10.1007/s00464-011-1799-6

4. Bittner R, Montgomery MA, Arregui E, Bansal V, Bingener J, Bisgaard T, Buhck H, Dudai M, Ferzli GS, Fitzgibbons RJ, Fortelny RH, Grimes KL, Klinge U, Kockerling F, Kumar S, Kukleta J, Lomanto D, Misra MC, Morales-Conde S, Reinpold W, Rosenberg J, Singh K, Timoney M, Weyhe D, Chowbey P (2015) Update of guidelines on laparoscopic (TAPP) and endoscopic (TEP) treatment of inguinal hernia (International Endohernia Society). Surg Endosc 29:289-321. https://doi.org/10.1007/ s00464-014-3917-8

5. Poelman MM, van den Heuvel B, Deelder JD, Abis GSA, Beudeker N, Bittner R, Campanelli G, van Dam D, Dwars BJ, Eker HH, Fingerhut A, Khatkov I, Kockerling F, Kukleta JF, Miserez M, Montgomery A, Munoz Brands RM, Morales-Conde S, Muysoms FE, Soltes M, Tromp W, Yavuz Y, Bonjer HJ (2013) EAES consensus development conference on endoscopic repair of groin hernias. Surg Endosc 27:3505-3519. https://doi. org/10.1007/s00464-013-3001-9

6. The HerniaSurg Group (2018) International guidelines for groin hernia management. Hernia 22:1-165. https://doi.org/10.1007/ s10029-017-1668-x

7. Köckerling F, Simons MP (2018) Current concepts of inguinal hernia repair. Visc Med 34:145-150. https://doi. org/10.1159/000487278

8. Köckerling F, Schug-Pass C (2014) Tailored approach in inguinal hernia repair-decision tree based on the guidelines. Front Surg 1:20. https://doi.org/10.3389/fsurg.2014.00020

9. Köckerling F, Lorenz R, Koch A (2019) Groin hernias in women - a review of the literature. Front Surg 6:4. https://doi. org/10.3389/fsurg.2019.00004

10. Köckerling F, Bittner R, Kofler M, Mayer F, Adolf D, Kuthe A, Weyhe D (2017) Lichtenstein versus total extraperitoneal patch plasty versus transabdominal patch plasty technique for primary unilateral inguinal hernia repair. Ann Surg 15:15-85. https://doi. org/10.1097/SLA.0000000000002541

11. Köckerling F, Schug-Pass C, Adolf D, Keller T, Kuthe A (2015) Bilateral and unilateral total extraperitoneal inguinal hernia repair (TEP) have equivalent early outcomes: analysis of 9395 cases. World J Surg 39:1887-1894. https://doi.org/10.1007/s0026 8-015-3055-z

12. Köckerling F, Jacob D, Wiegank W, Hukauf Schug-Pass C, Kuthe A, Bittner R (2016) Endoscopic repair of primary vs recurrent male unilateral inguinal hernias-are there differences in the outcome? Surg Endosc 30:1146-1155. https://doi.org/10.1007/ s00464-015-4318-3

13. Liberati A, Altman DG, Tetzlaff J, Mulrow C, Gøtzsche Ioannidis JPA (2009) The PRISMA statement for reporting systematic reviews and meta-analyses of studies that evaluate health care interventions: explanation and elaboration. PLoS Med 6(7):85. https://doi.org/10.1371/journal.pmed.1000100

14. Koning GG, Wetterslev J, van Laarhoven CJHM, Kreus F (2013) The totally extraperitoneal method versus Lichtenstein's technique for inguinal hernia repair: a systematic review with metaanalyses and trial sequential analyses of randomized clinical trials. PLoS One 8(1):e52599

15. Andersson B, Hallen M, Leveau P, Bergenfelz A, Westerdahl J (2003) Laparoscopic extraperitoneal inguinal hernia repair versus open mesh repair: a prospective randomized controlled trial. Surgery 133:464-472. https://doi.org/10.1067/msy.2003.98
16. Colak T, Aakca T, Kanik A, Aydin S (2003) Randomized clinical trial comparing laparoscopic totally extraperitoneal approach with open mesh repair in inguinal hernia. Surg Laparosc Endosc Percutan Tech 13:191-195

17. Eklund A, Rudberg C, Smedberg S, Enander LK, Leijonmarck C, Österberg J, Montgomery A (2006) Short-term results of a randomized clinical trial comparing Lichtenstein open repair with totally extraperitoneal laparoscopic inguinal hernia repair. Br J Surg 93:1060-1068. https://doi.org/10.1002/bjs.5405

18. Gokalp A, Inal M, Maralcan G, Baskonus I (2003) A prospective randomized study of lichtenstein open tension-free versus laparoscopic totally extraperitoneal techniques for inguinal hernia repair. Acta Chir Belg 103:502-506

19. Heikkinen TJ, Haukipuro K, Koivakangas P, Hulkko A (1998) A prospective randomized outcome and cost comparison of totally extraperitoneal endoscopic hernioplasty versus Lichtenstein hernia repair among employed patients. Surg Laparosc Endos $8: 338-344$

20. Hildebrandt J, Levantin O (2003) Tension-free methods of surgery of primary inguinal hernias. Comparison of endoscopic, total extraperitoneal hernioplasty with the Lichtenstein operation. Chirurg 74:915-921. https://doi.org/10.1007/s00104-003-0687-6

21. Merello J, Guerra AG, Madriz J, Guerra GG (1997) Laparoscopic TEP versus open Lichtenstein hernia repair. Surg Endosc 11:545

22. Moreno-Egea A, Aguayo JL (1999) Cirugia laparoscopica totalmente extraperitoneal frente a operacion de Lichtenstein en el tratamiento de la hernia inguinal. Cir Esp 66:53-57

23. Neumayer L, Giobbie-Hurder A, Jonasson O, Fitzgibbons R Jr, Dunlo D, Gibbs J et al (2004) Open mesh versus laparoscopic mesh repair of inguinal hernia. N Engl J Med 350(18):18191827. https://doi.org/10.1056/NEJMoa040093

24. Lal P, Kajla RK, Chander J, Saha R, Ramteke VK (2003) Randomized controlled study of laparoscopic total extraperitoneal vs open Lichtenstein inguinal hernia repair. Surg Endosc 17:850 856. https://doi.org/10.1007/s00464-002-8575-6

25. Langeveld HR, van't Riet M, Weidema WF et al (2010) Total extraperitoneal inguinal hernia repair compared with Lichtenstein (the LEVEL-trial): a randomized controlled trial. Ann Surg 251:819-824. https://doi.org/10.1097/SLA.0b013e3181 $\mathrm{d} 96 \mathrm{c} 32$

26. Lau H, Patil NG, Yuen WK (2006) Day-case endoscopic totally extraperitoneal inguinal hernioplasty versus open Lichtenstein hernioplasty for unilateral primary inguinal hernia in males: a randomized trial. Surg Endosc 20:76-81. https://doi. org/10.1007/s00464-005-0203-9

27. Wright DM, Kennedy A, Baxter JN, Fullarton GM, Fife LM, Sunderland GT, O'Dwyer PJ (1996) Early outcome after open versus extraperitoneal endoscopic tension-free hernioplasty: a randomized clinical trial. Surgery 119:552-557

28. Bobo Z, Nan W, Qin Q, Tao W, Jianguo L, Xianli H (2014) Meta-analysis of randomized controlled trials comparing Lichtenstein and totally extraperitoneal laparoscopic hernioplasty in treatment of inguinal hernias. J Surg Res 192:1-12. https://doi.org/10.1016/j.jss.2014.05.082

29. Wang WJ, Chen JZ, Fang Q, Li JF, Jin PF, Li ZT (2013) Comparison of the effects of laparoscopic hernia repair and Lichtenstein tension-free. hernia repair. J Laparoendosc Adv Surg Tech A 23:301-305. https://doi.org/10.1089/lap.2012.0217

30. Kouhia STH, Huttunen R, Silvasti SO, Heiskanan JT, Ahtola $\mathrm{H}$, Uotila-Nieminen M et al (2009) Lichtenstein hernioplasty versus totally extraperitoneal laparoscopic hernioplasty in treatment of recurrent inguinal hernia-a prospective randomized trial. Ann Surg 249:384-387. https://doi.org/10.1097/ SLA.0b013e318196d0b0

31. Eklund AS, Montgomery AK, Rasmussen C, Sandbue RP, Bergkvist LA, Rudberg CR (2009) Low recurrence rate after 
laparoscopic (TEP) and open (Lichtenstein). Inguinal Hernia Repair. Ann Surg 249(1):33-38. https://doi.org/10.1097/ SLA.0b013e31819255d0

32. Eklund A, Montgomery A, Bergkvist L, Rudberg C, Swedish Multicentre Trial of Inguinal Hernia Repair by Laparoscopy (SMIL) study group (2010) Chronic pain 5 years after randomized comparison of laparoscopic and Lichtenstein. inguinal hernia repair. Br J Surg 97:600-608. https://doi.org/10.1002/ bjs. 6904

33. Hallen M, Bergenfelz A, Westerdahl J (2008) Laparoscopic extraperitoneal inguinal hernia repair versus open mesh repair: long-term follow-up of a randomized controlled trial. Surgery 143:313-317. https://doi.org/10.1016/j.surg.2007.09.028

34. Pokorny H, Klingler A, Schmid T, Fortelny R, Hollinsky C, Kawji R et al (2008) Recurrence and complications after laparoscopic versus open inguinal hernia repair: results of a prospective randomized multicenter trial. Hernia 12:385-389. https://doi.org/10.1007/s10029-008-0357-1

35. Zhiping T, Min T, Jincheng $Z$ et al (2007) Randomized comparative study on totally extra-peritoneal prosthetic and tension-free herniorrhaphy. J Laparosc Surg 12:391

36. Dedemadi G, Sgourakis G, Karaliotas C, Christofides T, Kouraklis G, Karaliotas C (2006) Comparison of laparoscopic and open tension-free repair of recurrent inguinal hernias: a prospective randomized study. Surg Endosc 20:1099-1104. https://doi.org/10.1007/s00464-005-0621-8

37. Bringman S, Ramel S, Heikkinen TJ, Englund T, Westman B, Anderberg B (2003) Tension-free inguinal hernia repair: TEP versus mesh-plug versus Lichtenstein. Ann Surg 237:142-147. https://doi.org/10.1097/01.SLA.0000041043.51412.03

38. Eklund A, Carlsson P, Rosenblad A, Montgomery A, Bergkvist $\mathrm{L}$, Rudberg C, Swedish multicentre trial of inguinal hernia repair by laparoscopy (SMIL) study group (2010) Long-term cost-minimization analysis comparing laparoscopic with open (Lichtenstein) inguinal hernia repair. Br J Surg 97:765-771. https://doi.org/10.1002/bjs.6945

39. Hamza Y, Gabr E, Hammadi H, Khalil R (2010) Four-arm randomized trial comparing laparoscopic and open hernia repairs. Int J Surg 8:25-28. https://doi.org/10.1016/j.ijsu.2009.09.010

40. Dahlstrand U, Sandblom G, Ljungdahl M, Wollert S, Gunnarsson U (2013) TEP under general anesthesia is superior to Lichtenstein under local anesthesia in terms of pain 6 weeks after surgery: results from a randomized clinical trial. Surg Endosc 27:3632-3638. https://doi.org/10.1007/s00464-013-2936-1

41. Dhankhar DS, Sharma N, Mishra T, Kaur N, Singh S, Gupta S (2014) Totally extraperitoneal repair under general anesthesia versus Lichtenstein repair under local anesthesia for unilateral inguinal hernia: a prospective randomized controlled trial. Surg Endosc 28:996-1002. https://doi.org/10.1007/s0046 4-014-3269-9

42. Eker HH, Langeveld HR, Klitsie PJ, van't Riet M, Stassen LP, Weidema WF et al (2012) Randomized clinical trial of total extraperitoneal inguinal hernioplasty vs Lichtenstein repair: a long-term follow-up study. Arch Surg 147:256-260. https://doi. org/10.1001/archsurg.2011.2023

43. Köckerling F, Stechemesser B, Hukauf M, Kuthe A, Schug-Pass C (2015) TEP vs Lichtenstein: which technique is better for the repair of primary unilateral inguinal hernias in men? Surg Endosc 30:3304-3313. https://doi.org/10.1007/s00464-015-4603-1

44. McCormack K, Wake BL, Fraser C, Vale L, Perez J, Grant A (2005) Transabdominal pre-peritoneal (TAPP) versus totally extraperitoneal (TEP) laparoscopic techniques for inguinal hernia repair: a systematic review. Hernia 9:109-114. https://doi. org/10.1007/s10029-004-0309-3

45. Wake BL, McCormack K, Fraser C, Vale L, Perez J, Grant A (2005) Transabdominal pre-peritoneal (TAPP) versus totally extraperitoneal (TEP) laparoscopic techniques for inguinal hernia repair: (review). Cochrane Database Syst Rev. https://doi. org/10.1002/14651858.cd004703.pub2

46. Bracale U, Melillo P, Pignata G, Di Salvo E, Rovani M, Merola G, Pecchia L (2012) Which is the best laparoscopic approach for inguinal hernia repair: TEP or TAPP? A systematic review of the literature with a network meta-analysis. Surg Endosc 26:33553366. https://doi.org/10.1007/s00464-012-2382-5

47. Antoniou SA, Antoniou GA, Bartsch DK, Fendrich V, Koch OO, Pointner R, Granderath FA (2013) Transabdominal preperitoneal versus totally extraperitoneal repair of inguinal hernia: a metaanalysis of randomized studies. Am J Surg 206:245-252. https ://doi.org/10.1016/j.amjsurg.2012.10.041

48. Wei FX, Zhang YC, Wei H, Zhang YL, Shao Y, Ni R (2015) Transabdominal pre-peritoneal (TAPP) versus totally extraperitoneal (TEP) for laparoscopic hernia repair: a meta-analysis. Surg Laparosc Endosc Percutan Tech 25:375-383. https://doi. org/10.1097/SLE.0000000000000123

49. Chen LS, Chen WC, Kang YN, Wu CC, Tsai LW, Liu MZ (2019) Effects of transabdominal preperitoneal and totally extraperitoneal inguinal hernia repair: an update systematic review and meta-analysis of randomized controlled trials. Surg Endosc 33:418-428. https://doi.org/10.1007/s00464-018-6314-x

50. Schrenk P, Woisetschläger R, Rieger R, Wayand W (1996) Prospective randomized trial comparing postoperative pain and return to physical activity after transabdominal preperitoneal, total preperitoneal or Shouldice technique for inguinal hernia repair. Br J Surg 83:1563-1566

51. Butler RE, Burke R, Schneider JJ, Brar H, Lucha PA Jr (2007) The economic impact of laparoscopic inguinal hernia repair: results of a double-blinded, prospective, randomized trial. Surg Endosc 21:387-390. https://doi.org/10.1007/s00464-006-9123-6

52. Gong K, Zhang N, Lu Y, Zhu B, Zhang Z, Du D, Zhao X, Jiang $H$ (2011) Comparison of the open tension-free mesh-plug, transabdominal preperitoneal (TAPP), and totally extraperitoneal (TEP) laparoscopic techniques for primary unilateral inguinal hernia repair: a prospective randomized controlled trial. Surg Endosc 25:234-239. https://doi.org/10.1007/s0046 4-010-1165-0

53. Krishna A, Misra MC, Bansal VK, Kumar S, Rajeshwari S, Chabra A (2012) Laparoscopic inguinal hernia repair: transabdominal preperitoneal (TAPP) versus totally extraperitoneal (TEP) approach: a prospective randomized controlled trial. Surg Endosc 26:639-649. https://doi.org/10.1007/s00464-011-1931-7

54. Zhu Q, Mao Z, Yu B, Jin J, Zheng M, Li J (2009) Effects of persistent $\mathrm{CO}(2)$ insufflation during different laparoscopic inguinal hernioplasty: a prospective, randomized, controlled study. J Laparoendosc Adv Surg Tech A 19:611-614. https://doi. org/10.1089/lap.2009.0084

55. Bansal VK, Misra MC, Babu D, Victor J, Kumar S, Sagar R et al (2013) A prospective, randomized comparison of long-term outcomes: chronic groin pain and quality of life following transabdominal preperitoneal (TAPP), and totally extraperitoneal (TEP) laparoscopic inguinal hernia repair. Surg Endosc 27:2373-2382. https://doi.org/10.1007/s00464-013-2797-7

56. Wang WJ, Chen JZ, Fang Q, Li JF, Jin PF, Li ZT (2013) Comparison of the effects of laparoscopic hernia repair and Lichtenstein tension-free hernia repair. J Laparoendosc Adv Surg Tech 23(4):301-305. https://doi.org/10.1089/lap.2012.0217

57. Ciftci F, Abdulrahman I, Ibrahimoglu F, Kilic G (2015) Earlystage quantitative analysis of the effect of laparoscopic versus conventional inguinal hernia repair on physical activity. Chirurgia 110:451-456

58. Mesci A, Korkmaz B, Dinckan A, Colak T, Balci N, Ogunc G (2012) Digital evaluation of the muscle functions of the lower extremities among inguinal hernia patients treated using 
three different surgical techniques: a prospective randomized study. Surg Today 42:157-163. https://doi.org/10.1007/s0059 5-011-0017-4

59. Sharma D, Yadav K, Hazrah P, Borgharia S, Lal R (2015) Prospective randomized trial comparing laparoscopic transabdominal preperitoneal (TAPP) and laparoscopic totally extra peritoneal (TEP) approach for bilateral inguinal hernias. Int J Surg 22:110-117. https://doi.org/10.1016/j.ijsu.2015.07.713

60. Günal Ö, Özer S, Gürleyik E, Bahcebasi T (2007) Does the approach to the groin make a difference in hernia repair? Hernia 11:429-434. https://doi.org/10.1007/s10029-007-0252-1

61. Bansal VK, Krishna A, Manek P, Kumar S, Prajapati O, Subramaniam R, Kumar A et al (2017) A prospective randomized comparison of testicular functions, sexual functions and quality of life following laparoscopic totally extra-peritoneal (TEP) and transabdominal preperitoneal (TAPP) inguinal hernia repairs. Surg Endosc 31:1478-1486. https://doi.org/10.1007/s0046 4-016-5142-0

62. Jeelani S, Suhail MS, Dar HM, Abass MF, Mushtaq A, Ali U (2015) A comparative study of transabdominal preperitoneal versus totally extra-peritoneal mesh repair of inguinal hernia. AMR. https://doi.org/10.5455/amr.20150403124300

63. Tam KW, Liang HH, Chai CY (2010) Outcomes of staple fixation of mesh versus nonfixation in laparoscopic total extraperitoneal inguinal repair: a meta-analysis of randomized controlled trials. World J Surg 34:3065-3074. https://doi.org/10.1007/s0026 8-010-0760-5

64. Teng YJ, Pan SM, Liu YL, Yang KH, Zhang YC, Tia JH, Han JX (2011) A meta-analysis of randomized controlled trials of fixation versus nonfixation of mesh in laparoscopic total extraperitoneal inguinal hernia repair. Surg Endosc 25:2849-2858. https://doi.org/10.1007/s00464-011-1668-3

65. Sajid MS, Ladwa N, Kalra L, Hutson K, Sains P, Baig MK (2012) A meta-analysis examining the use of tacker fixation versus nofixation of mesh in laparoscopic inguinal hernia repair. Int J Surg 10:224-231. https://doi.org/10.1016/j.ijsu.2012.03.001

66. Ferzli GS, Frezza EE, Pecoraro AM, Dee Ahern K (1999) Prospective randomized study of stapled versus unstapled mesh in a laparoscopic peritoneal inguinal hernia repair. J Am Coll Surg 188:461-465

67. Koch CA, Greenlee SM, Larson DR, Harrington JR, Farley DR (2006) Randomized prospective study of totally extraperitoneal inguinal hernia repair: fixation versus no fixation of mesh. JSLS 10:457-460

68. Moreno-Egea A, Torralba Martinez A, Morales Cuenca G, Aguayo Albasini JL (2004) Randomized clinical trial of fixation vs nonfixation of mesh in total extraperitoneal inguinal hernioplasty. Arch Surg 139:1376-1379

69. Parshad R, Kumar R, Hazrah P, Bal S (2005) A randomized comparison of the early outcome of stapled and unstapled techniques of laparoscopic total extraperitoneal inguinal hernia repair. JSLS 9:403-407

70. Taylor C, Layani L, Liew V, Ghusn M, Crampton N, White S (2008) Laparoscopic inguinal hernia repair without mesh fixation, early results of a large randomized clinical trial. Surg Endosc 22:757-762. https://doi.org/10.1007/s00464-007-9510-7

71. Lau H, Patil NG (2003) Selective non-stapling of mesh during unilateral endoscopic total extraperitoneal inguinal hernioplasty. Arch Surg 138:1352-1355

72. Li JW, Zheng MH, Li HQ, Zhang H, Hu WG, Wang ML (2007) A randomized controlled clinical trial comparing stapling with non-stapling of mesh in laparoscopic total extraperitoneal inguinal hernioplasty. Chin J Gen Surg 22:440-442

73. Garg P, Nair S, Shereef M, Thakur JD, Nain N, Menon GR, Ismail M (2011) Mesh fixation compared to nonfixation in total extraperitoneal inguinal hernia repair: a randomized controlled trial in a rural center in India. Surg Endosc 25:3300-3306. https ://doi.org/10.1007/s00464-011-1708-z

74. Gutlic N, Rogmark P, Nordin P, Petersson U, Montgomery A (2016) Impact of mesh fixation on chronic pain in total extraperitoneal inguinal hernia repair (TEP). A nationwide registerbased study. Ann Surg 263:1199-1206. https://doi.org/10.1097/ SLA.0000000000001306

75. Currie A, Andrew H, Tonsi A, Hurley PR, Taribagil S (2012) Lightweight versus heavyweight mesh in laparoscopic inguinal hernia repair: a meta-analysis. Surg Endosc 26:2126-2133. https ://doi.org/10.1007/s00464-012-2179-6

76. Sajid MS, Kalra L, Parampalli U, Sains PS, Baig MK (2013) A systematic review and meta-analysis evaluating the effectiveness of lightweight mesh against heavyweight mesh in influencing the incidence of chronic groin pain following laparoscopic inguinal hernia repair. Am J Surg 205:726-736. https://doi.org/10.1016/j. amjsurg.2012.07.046

77. Bringman S, Wollert S, Osterberg J, Heikkinen T (2005) Early results of a randomized multicenter trial comparing Prolene and Vypro II mesh in bilateral endoscopic extraperitoneal hernioplasty (TEP). Surg Endosc 19:536-540. https://doi.org/10.1007/ s00464-004-9100-x

78. Heikkinen T, Wollert S, Österberg J, Smedberg S, Bringman S (2006) Early results of a randomized trial comparing Prolene and Vypro II mesh in endoscopic extraperitoneal inguinal hernia repair (TEP) of recurrent unilateral hernias. Hernia 10:34-40. https://doi.org/10.1007/s10029-005-0026-6

79. Agarwal BB, Agarwal KA, Mahajan KC (2009) Prospective double-blind randomized controlled study comparing heavy- and lightweight polypropylene mesh in totally extraperitoneal repair of inguinal hernia: early results. Surg Endosc 23:242-247. https ://doi.org/10.1007/s00464-008-0188-2

80. Chowbey PK, Garg N, Sharma A, Khullar R, Soni V, Baijal M, Mittal T (2010) Prospective randomized clinical trial comparing lightweight mesh and heavyweight polypropylene mesh in endoscopic totally extraperitoneal groin hernia repair. Surg Endosc 24:3073-3079. https://doi.org/10.1007/s00464-010-1092-0

81. Chui LB, Ng WT, Sze YS, Yuen KS, Wong YT, Kong CK (2010) Prospective, randomized, controlled trial comparing lightweight versus heavyweight mesh in chronic pain incidence after TEP repair of bilateral inguinal hernia. Surg Endosc 24:2735-2738. https://doi.org/10.1007/s00464-010-1036-8

82. Peeters E, Spiessens C, Oyen R, De Wever L, Vanderschueren D, Penninckx F, Miserez M (2010) Laparoscopic inguinal hernia repair in men with lightweight meshes may significantly impair sperm motility. Ann Surg 252:240-246. https://doi.org/10.1097/ SLA.0b013e3181e8fac5

83. Burgmans JPJ, Voorbrood EH, Simmermacher RKJ, Schouten N, Smakman N, Clevers GJ et al (2016) Long-term results of a randomized double-blinded prospective trial of lightweight (Ultrapro) versus a heavyweight mesh (Prolene) in laparoscopic total extraperitoneal inguinal hernia repair (TULP-trial). Ann Surg 263:862-866. https://doi.org/10.1097/SLA.0000000000 001579

84. Roos M, Bakker WJ, Schouten N, Voorbrood C, Clevers GJ, Verkeisdonk EJ, Davids P, Burgmans J (2018) Higher recurrence rate after endoscopic totally extraperitoneal (TEP) inguinal hernia repair with Ultrapro lightweight mesh. Ann Surg 268:241246. https://doi.org/10.1097/SLA.0000000000002649

85. Melkemichel M, Bringman S, Widhe B (2018) Lower recurrence rate with heavyweight mesh compared to lightweight mesh in laparoscopic totally extra-peritoneal (TEP) repair of groin hernia: a nationwide population-based register study. Hernia 22:989997. https://doi.org/10.1007/s10029-018-1809-x 
86. Tong YS, Wu CC, Bai CH, Lee HC, Liang HH, Kuo LJ, Wei PL, Tam KW (2014) Effect of extraperitoneal bupivacaine analgesia in laparoscopic inguinal hernia repair: a meta-analysis of randomized controlled trials. Hernia 18:177-183. https://doi. org/10.1007/s10029-013-1100-0

87. Saff GN, Marks RA, Kuroda M, Rozan JP, Hertz R (1998) Analgesic effect of bupivacaine on extraperitoneal laparoscopic hernia repair. Anesth Analg 87:377-381

88. O'Riordain DS, Kelly P, Horgan PG, Keane FBV, Tanner WA (1998) A randomized controlled trial of extraperitoneal bupivacaine analgesia in laparoscopic inguinal hernia repair. Am J Surg 176:254-257

89. Bar-Dayn A, Natour M, Bar-Zakai B, Zmora O, Shabtai M, Ayalon A, Kuriansky J (2004) Preperitoneal bupivacaine attenuates pain following laparoscopic inguinal hernia repair. Surg Endosc 18:1079-1081. https://doi.org/10.1007/s0046 4-003-8214-x

90. Suvikapakornku R, Valaivarangkul P, Noiwan P, Phansukphon $\mathrm{T}$ (2009) A randomized controlled trial of preperitoneal bupivacaine instillation for reducing pain following laparoscopic inguinal herniorrhaphy. Surg Innov. https://doi.org/10.1177/15533 50609334128

91. Hon SF, Poon CM, Leong HT, Tang YC (2009) Pre-emptive infiltration of bupivacaine in laparoscopic total extraperitoneal hernioplasty: a randomized controlled trial. Hernia 13:53-56. https://doi.org/10.1007/s10029-008-0422-9

92. Kumar S, Joshi M, Chaudhary S (2009) 'Dissectalgia' following TEP, a new entity: its recognition and treatment. Result of a prospective randomized controlled trial. Hernia 13:591-596. https://doi.org/10.1007/s10029-009-0538-6

93. Subwongcharoen S, Udompornmongkok V (2010) A randomized control trial of levobupivacaine, bupivacaine versus placebo extraperitoneal infusion in totally extraperitoneal laparoscopic inguinal hernioplasty. J Surg Res 162:279-283. https://doi. org/10.1016/j.jss.2009.01.030

94. Abbas MH, Hamade A, Choudhry MN, Hamza N, Nadeem R, Ammori BJ (2010) Infiltration of wounds and extraperitoneal space with local anesthetic in patients undergoing laparoscopic totally extraperitoneal repair of unilateral inguinal hernias: a randomized double-blind placebo-controlled trial. Scand J Surg 99:18-23

95. Fan JKM, Liu J, Chen K, Yang X, Xu X, Choi HK, Chan FSY, Chiu KWH, Lo CM (2018) Preperitoneal closed-system suction drainage after totally extraperitoneal hernioplasty in the prevention of early seroma formation: a prospective double-blind randomized controlled trial. Hernia 22:455-465. https://doi. org/10.1007/s10029-018-1731-2

96. Tolver MA, Rosenberg J, Bisgaard T (2016) Convalescence after laparoscopic inguinal hernia repair: a qualitative systematic review. Surg Endosc 30:5165-5172. https://doi.org/10.1007/ s00464-016-4863-4

97. Tolver MA, Rosenberg J, Bisgaard T (2012) Early pain after laparoscopic inguinal hernia repair: a qualitative systematic review. Acta Anastehsiol Scand 56:549-557. https://doi.org/10. 1111/j.1399-6576.2011.02633.x

98. Öberg S, Andresen K, Klausen TW, Rosenberg J (2018) Chronic pain after mesh versus nonmesh repair of inguinal hernias: a systematic review and a network meta-analysis on randomized controlled trials. Surgery 163:1151-1159. https://doi.org/10.1016/j. surg.2017.12.017

99. Hoffman H, Walther D, Bittner R, Köckerling F, Adolf D, Kirchhoff $P$ (2018) Smaller inguinal hernias are independent risk factors for developing chronic postoperative inguinal pain (CPIP). Ann Surg 15:85. https://doi.org/10.1097/sla.0000000000003065

100. Kordzadeh A, Liu MO, Jayanthi NV (2017) Male infertility following inguinal hernia repair: a systematic review and pooled analysis. Hernia 13:591-596. https://doi.org/10.1007/s1002 9-009-0538-6

101. Skawran S, Weyhe D, Schmitz D, Belyaev O, Bauer KH (2011) Bilateral endoscopic total extraperitoneal (TEP) inguinal hernia repair does not induce obstructive azoospermia: data of a retrospective and prospective trial. World J Surg 35:1643-1648. https ://doi.org/10.1007/s00268-011-1072-0

102. Peeters E, Spiessens C, Oyen R, De Wever L, Vanderschueren D, Penninckx F, Miserez M (2014) Sperm motility after laparoscopic inguinal hernia repair with lightweight meshes: 3-year follow-up of a randomized clinical trial. Hernia 18:361-367. https://doi.org/10.1007/s10029-012-1028-9

103. Shouten N, van Dalen T, Smakman N, Elias S, van de Water C, Spermon RJ, Mulder LS, Burgmans PJ (2012) Male infertility after endoscopic totally extraperitoneal (TEP) hernia repair (Main): rational and design of a prospective observational cohort study. BMC Surg 12:7. http://www.biomedcentral. co/1471-2482/12/7

104. Dong Z, Kujawa SA, Wang C, Zhao H (2018) Does the use of hernia mesh in surgical inguinal hernia repairs cause male infertility? A systematic review and descriptive analysis. Reprod Health 15:69. https://doi.org/10.1186/s12978-018-0510-y

105. Lal P, Bansal B, Sharma R, Pradhan G (2016) Laparoscopic TEP repair of inguinal hernia does not alter testicular perfusion. Hernia 20:429-434. https://doi.org/10.1007/s10029-016-1479-5

106. Singh AN, Bansal VK, Misra MC, Kumar S, Rajeshwari S, Kumar A, Sagar R, Kumar A (2012) Testicular functions, chronic groin pain, and quality of life after laparoscopic an open mesh repair of inguinal hernia: a prospective randomized controlled trial. Surg Endosc 26:1304-1317. https://doi.org/10.1007/s0046 4-011-2019-y

107. Akbulut G, Serteser M, Yücel A, Degirmenci B, Yilmaz S, Polat C et al (2003) Can laparoscopic hernia repair age function and volume of testis. Randomized clinical trial. Surg Laparosc Endosc Percutan Tech 13:377-381

108. Köckerling F (2018) What is the influence of simulation-based training courses, the learning curve, supervision, and surgeon volume on the outcome in hernia repair? A systematic review. Front Surg 5:57. https://doi.org/10.3389/fsurg.2018.00057

109. Köckerling F, Bittner R, Kraft R, Hukauf M, Kuthe A, SchugPass C (2017) Does surgeon volume matter in the outcome of endoscopic inguinal hernia repair? Surg Endosc 31:573-585. https://doi.org/10.1007/s00464-016-5001-z

110. AlJamal YN, Zendejas B, Gas BL, Ali SM, Heller SF, Kendrick ML, Farley DR (2016) Annual surgeon volume and patient outcomes following laparoscopic totally extraperitoneal inguinal hernia repairs. J Laparoendosc Adv Surg Tech 26(2):92-98

111. Aikoye A, Harilingam M, Khushal A (2015) The impact of high surgical volume on outcomes from laparoscopic (totally extra peritoneal) inguinal hernia repair. J Clin Diagn Res 9:15-16

112. Kuthe A, Saemann T, Tamme C, Köckerling F (1998) Technique of total extraperitoneal endoscopic hernioplasty of the inguinal canal. Zentralbl Chir 123:1428-1435

113. Köckerling F (2017) Evidence-based TEP technique. Chirurg 88:288-295. https://doi.org/10.1007/s00104-016-0360-5

114. Köckerling F, Chowbey P, Lomanto D, Arregui M (2018) Technique total extraperitoneal patchplasty: standard technique and specific risks. In: Bittner R, Köckerling F, Fitzgibbons R, LeBlanc K, Mittal S, Chowbey P (eds) Laparo-endoscopic hernia surgery-evidence based clinical practice. Springer, Heidelberg

115. Tamme C, Scheidbach H, Hampe C, Schneider C, Köckerling F (2003) Totally extraperitoneal endoscopic inguinal hernia repair (TEP). Surg Endosc 17:190-195. https://doi.org/10.1007/s0046 4-002-8905-8

116. Scheuerlein H, Schiller A, Schneider C, Scheidbach H, Tamme C, Köckerling F (2003) Totally extraperitoneal repair of 
recurrent inguinal hernia. Surg Endosc 17:1072-1076. https:// doi.org/10.1007/s00464-002-8957-9

117. Tamme C, Garde N, Klingler A, Hampe C, Wunder R, Köckerling F (2005) Totally extraperitoneal inguinal hernioplasty with titanium-coated lightweight polypropylene mesh: early results. Surg Endosc 19:1125-1129. https://doi.org/10.1007/s0046 4-004-8219-0
Publisher's Note Springer Nature remains neutral with regard to jurisdictional claims in published maps and institutional affiliations. 